\title{
Advanced Presentation of BETHSY 6.2TC Test Results Calculated by RELAP5 and TRACE
}

\author{
Andrej Prošek and Ovidiu-Adrian Berar \\ Reactor Engineering Division, Jožef Stefan Institute, Jamova Cesta 39, SI-1000 Ljubljana, Slovenia \\ Correspondence should be addressed to Andrej Prošek, andrej.prosek@ijs.si
}

Received 16 December 2011; Revised 23 March 2012; Accepted 10 April 2012

Academic Editor: Stephen M. Bajorek

Copyright (C) 2012 A. Prošek and O.-A. Berar. This is an open access article distributed under the Creative Commons Attribution License, which permits unrestricted use, distribution, and reproduction in any medium, provided the original work is properly cited.

\begin{abstract}
Today most software applications come with a graphical user interface, including U.S. Nuclear Regulatory Commission TRAC/RELAP Advanced Computational Engine (TRACE) best-estimate reactor system code. The graphical user interface is called Symbolic Nuclear Analysis Package (SNAP). The purpose of the present study was to assess the TRACE computer code and to assess the SNAP capabilities for input deck preparation and advanced presentation of the results. BETHSY 6.2 TC test was selected, which is $15.24 \mathrm{~cm}$ equivalent diameter horizontal cold leg break. For calculations the TRACE V5.0 Patch 1 and RELAP5/MOD3.3 Patch 4 were used. The RELAP5 legacy input deck was converted to TRACE input deck using SNAP. The RELAP5 and TRACE comparison to experimental data showed that TRACE results are as good as or better than the RELAP5 calculated results. The developed animation masks were of great help in comparison of results and investigating the calculated physical phenomena and processes.
\end{abstract}

\section{Introduction}

The TRAC/RELAP Advanced Computational Engine (TRACE) is the latest in a series of advanced best-estimate reactor systems codes developed by the US Nuclear Regulatory Commission (US NRC) [1]. The advanced TRACE computer code comes with a graphical user interface (GUI) called SNAP (Symbolic Nuclear Analysis Package) [2], which is intended for pre- and postprocessing, running the codes, RELAP5 to TRACE input deck conversion, input deck database generation, and so forth. Also other advanced thermal-hydraulic codes, for example RELAP5-3D [3] and MARS come with GUI [4]. According to [4] MARS has a simple GUI, which is provided for program execution and to display the calculation results online. On the other hand, RELAP5-3D can also use SNAP as GUI.

The advanced TRACE computer code is still under development and it will have all capabilities of RELAP5 [5]. Although the TRACE computer code is the future of US NRC, its use in countries members of Code Applications and Maintenance Program (CAMP) it is still not dominant against the RELAP5 computer code. Nevertheless, TRACE is now more and more used [6-8], also by RELAP5 users, because of better RELAP5 to TRACE conversion capability using SNAP as reported on CAMP meetings [9-11]. However, not much information is available in the open literature on RELAP5 to TRACE conversion. In general, the typical RELAP5 users start with RELAP5 legacy input deck, which is first automatically converted to TRACE input decks using SNAP and then manual corrections are done. Namely, much of efforts were done in the past to develop the RELAP5 input decks. The purpose of the present study was therefore to show advances in safety analysis using SNAP regarding input deck preparation and graphical presentation of the results (including animations) comparing to traditional ASCII editing the input model and extracting the calculated data from restart-plot files for graphical comparison. Such tools finally contribute to better assessment of the advanced TRACE code. In the paper the TRACE assessment against BETHSY 6.2TC test is presented. TRACE input model is converted and adapted RELAP5 input model, which was developed in the past for international standard problem no. 27 (ISP-27) at Institut "Jožef Stefan" (IJS) [12]. The RELAP5 legacy input deck developed at IJS is 
different than the one which has been used for conversion to TRACE in the original TRACE code assessment study [13]. In the TRACE code assessment study [13] it was concluded that the timing of core heatup is of a concern for the BETHSY 6.2TC test. This motivated the authors to make their own TRACE calculation of the BETHSY 6.2TC test, besides the fact that RELAP5 and TRACE results can be directly compared too. When comparing results of two different codes with the experimental data it can be more easily judged, if the differences between the calculation and measured data are due to the code, or other reasons (e.g., nodalization). When comparing our TRACE calculation to the RELAP5 calculation and to TRACE calculation described in the code assessment manual [13], one can more easily see the peculiarities of the TRACE code. Finally, RELAP5 and TRACE calculations were compared between each other using animation masks, which presents advanced analysis technique. Finally, the procedure for conversion input deck from RELAP5 to TRACE is presented, which is practically not available in the open literature.

\section{Methodology Description}

The selected BETHSY $6.2 \mathrm{TC}$ test was $15.24 \mathrm{~cm}$ (6 inch) equivalent diameter horizontal cold leg break in the reference pressurized water reactor without high pressure and low pressure safety injection. The transient ended at $2179 \mathrm{~s}$ when primary pressure dropped below $0.7 \mathrm{MPa}$. BETHSY facility was a 3-loop replica of a 900 MWe Framatome pressurized water reactor. For calculations the RELAP5/MOD3.3 Patch 4 [14] and TRACE V5.0 Patch 1 computer codes were used [1]. The TRACE input model was obtained by conversion from RELAP5 input model using SNAP and manual corrections and additions. For better presentation of the calculated physical phenomena and processes, animation models using SNAP were developed for displaying results obtained by RELAP5 and TRACE.

In the following subsections the BETHSY facility and test scenario are described first. Then the RELAP5 and TRACE input models are described. At the end, the RELAP5 and TRACE computer codes and SNAP tool are described briefly.

2.1. Description of BETHSY Integral Test Facility. BETHSY was an integral test facility, which was designed to simulate most pressurized water reactor accidents of interest, study accident management procedures and validate the computer codes. It was a scaled down model of three-loop Framatome (now AREVA NC) nuclear power plant with the thermal power $2775 \mathrm{MW}$ (see Figure 1). Volume, mass flow and power were scaled to $1: 96.9$, while the elevations and the pressures of the primary and secondary system were preserved [15]. The core power has been limited to approximately $10 \%$ of nominal value, that is, $3 \mathrm{MW}$. This means that the power was limited to the decay heat level and the transients without reactor trip could not be simulated. The design pressure on the primary side was $17.2 \mathrm{MPa}$ and on the secondary side $8 \mathrm{MPa}$. There were 428 electrically heated rods, which could reach $1273 \mathrm{~K}$. Like in the reference reactor, the BETHSY facility had three identical loops, each equipped with a main coolant pump and an active steam generator (see Figure 1). Every primary- and secondaryside-engineered safety system was simulated. This included high and low pressure safety injection systems, accumulators (one per loop), pressurizer spray and relief circuits, auxiliary feedwater system, and steam dumps to the atmosphere and to the condenser.

The break system enabled simulation of the break in different locations, that is, in cold leg, lower plenum, pressurizer, steam generator $U$ tubes and feedwater pipe. The instrumentation data system measured all data needed for the transient analysis. The control system could simulate the plant control systems and operator actions.

2.2. BETHSY 6.2TC Test Description. BETHSY 6.2TC test was a $15.24 \mathrm{~cm}$ (6 inch) cold leg break in the loop no. 1 without available high pressure and low pressure safety injection system [6]. This test is a counterpart test of LSTF SB-CL-21 [16]. To duplicate test as closely as possible, the BETHSY upper head/downcomer bypass was modified to take account of LSTF $(0.28 \%$ of the total flow in the three loops at LSTF nominal conditions). The pressurizer was connected to the broken loop. The sprays and heaters were not used. The core power was maintained at a constant level in the period from break opening time till the time of scram plus $8 \mathrm{~s}$. Then the core power followed the LSTF curve. Primary circuit charging and letdown system were not used. Accumulators were available in the intact loops. Until the scram the secondary pressure was maintained constant at approximately 6.8 $\mathrm{MPa}$. After scram signal, the condenser was isolated and the atmospheric relief valves were used to control pressure at 7.2 $\mathrm{MPa}$. The main feedwater supply was also stopped at scram signal, while the auxiliary feedwater system was assumed not operable.

The main aims of BETHSY 6.2TC test were to compare the counterpart test data from BETHSY and LSTF facilities and qualification of CATHARE 2 computer code. The experiment started with the opening of the valve simulating the break in the cold leg no. 1 at the time $0 \mathrm{~s}$. Sudden primary pressure drop caused scram signal when pressure was below 13.0 MPa and safety injection (SI) signal was generated, when primary pressure was below $11.7 \mathrm{MPa}$. At scram signal all three primary pumps were stopped and natural circulation regime took over the primary system. The hot parts of the primary circuit (upper head, upper plenum, SG U-tubes) started to boil. The formation of loop seal caused the core level depression. The drop in the core-collapsed liquid level was stopped at $134 \mathrm{~s}$ by loop seal clearance on the three loops. The loop seal clearance occurred at the same time on all three loops. After loop seal clearance the core liquid level rose again due to pressure balances and then started to drop again due to inventory loss through the break. When primary pressure dropped below $4.2 \mathrm{MPa}$, the accumulator injection started, which recovered the core. The accumulator injection was stopped on the basis of low level criterion. After it stopped, in the absence of high pressure injection, the primary circuit emptied through the break and third 


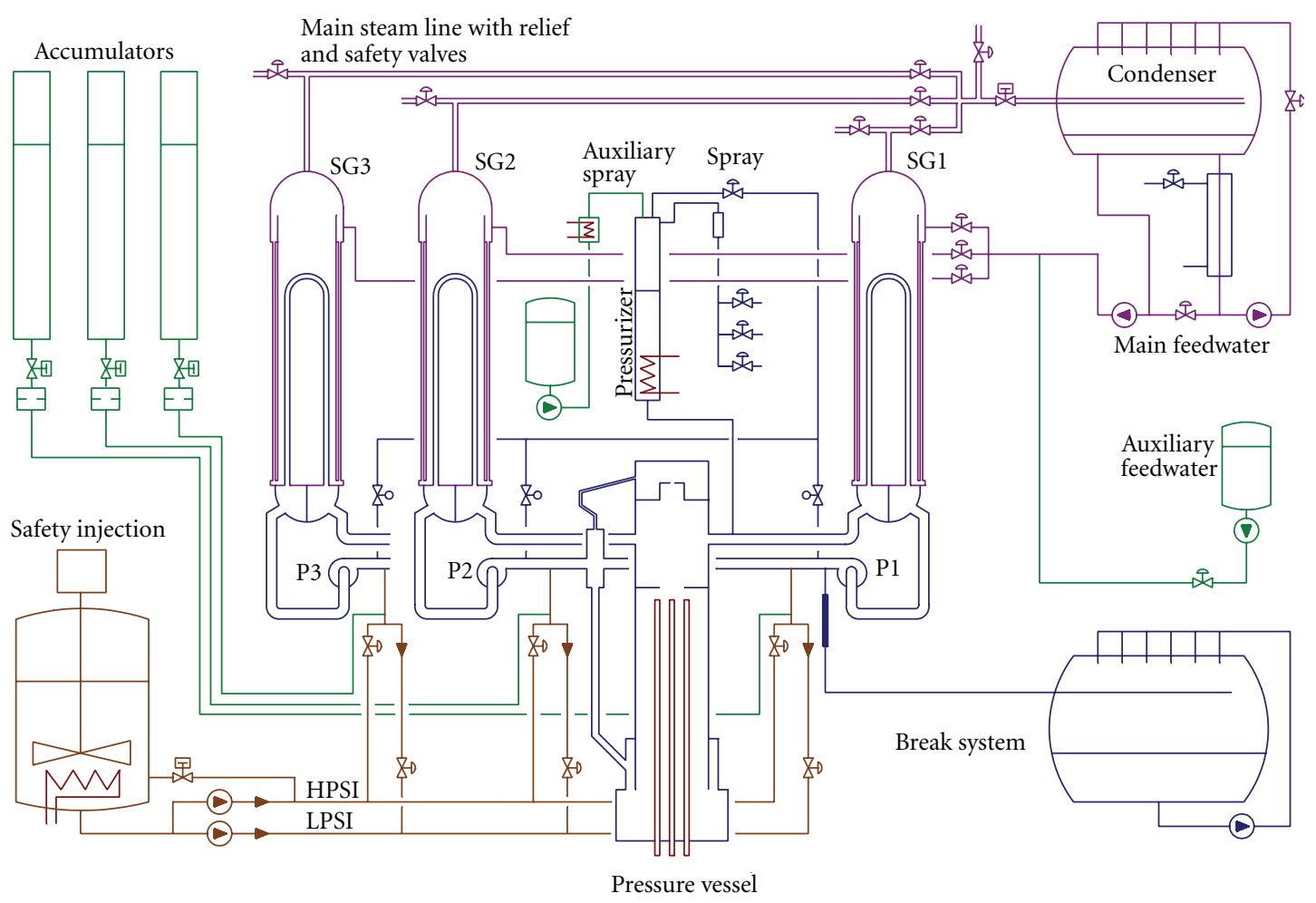

FIgURE 1: BETHSY schematic diagram.

core uncovery occurred. The low pressure injection was not activated by assumption. The test was ended when the primary pressure dropped below $0.7 \mathrm{MPa}$.

2.3. RELAP5 Input Model Description. The base RELAP5/ MOD3.3 Patch 4 input model of BETHSY has been developed first, which is described in detail in [17]. In the following brief description is given. The RELAP5/MOD2 input model was developed, when participating to ISP-27. This base RELAP5/MOD2 input model was later upgraded to RELAP5/MOD3.1 and RELAP5/MOD3.1.2 and RELAP5/ MOD3.2 models [12]. The RELAP5/MOD3.2 input model was developed for all available BETHSY tests consisting from 398 volumes, 408 junctions, and 402 heat structures $[18,19]$. This model was in 2010 adapted for the use with the RELAP5/MOD3.3 computer code. No changes were made to the geometry and the number of hydrodynamic components and heat structures. From the RELAP5/MOD3.3 ASCII input model the hydrodynamic view was generated by SNAP, requiring also manual editing in SNAP Model Editor. The SNAP hydrodynamic components view of RELAP5/MOD3.3 input model for BETHSY 6.2TC transient is shown in Figure 2. The artificial pressurizer pressure and level control needed for steady-state calculation are switched off during transient calculation. There are 151 hydraulic components and 72 heat structures.

2.4. TRACE Input Model Description. The TRACE input model was converted from RELAP5/MOD3.3 input model. For conversion the SNAP was used. The SNAP conversion to TRACE mostly preserved the RELAP5 numbering of components (see [1] and compare Figures 2 and 3). The converted TRACE input model consisted of 172 hydraulic components and 72 heat structures and was not running. Several manual corrections and adaptations of components were needed. The final view of adapted TRACE input model for transient calculation is shown in Figure 3. It consists of 160 hydraulic components, while the number of heat structures was preserved.

All converted hydraulic diameters were replaced manually with the hydraulic diameters obtained from the RELAP5/ MOD3.3 output file. The nitrogen vessel represented by an Accumulator component in the RELAP5 input model was automatically converted to Liquid separator type instead of Accumulator type of Pipe component. It was then manually changed to Accumulator type of pipe. SNAP 1.2.6 conversion tool failed short in the respect of converting the wall-roughness for some hydraulic components from RELAP5 to TRACE. The data for the wall-roughness for these components were therefore manually added to the TRACE input model. Problems were also found with Separator component-RELAP5 liquid carryover and carryunder value were converted to minimum and maximum barrel void fraction, while to liquid carryover and carryunder other values were assigned.

For TRACE input model the calculated area of adjacent volumes are also compared in SNAP. If the volumes differ by more than a user-modifiable ratio, the volumes are determined to involve an area change. An error is reported if the intervening edge between the two volumes does not 


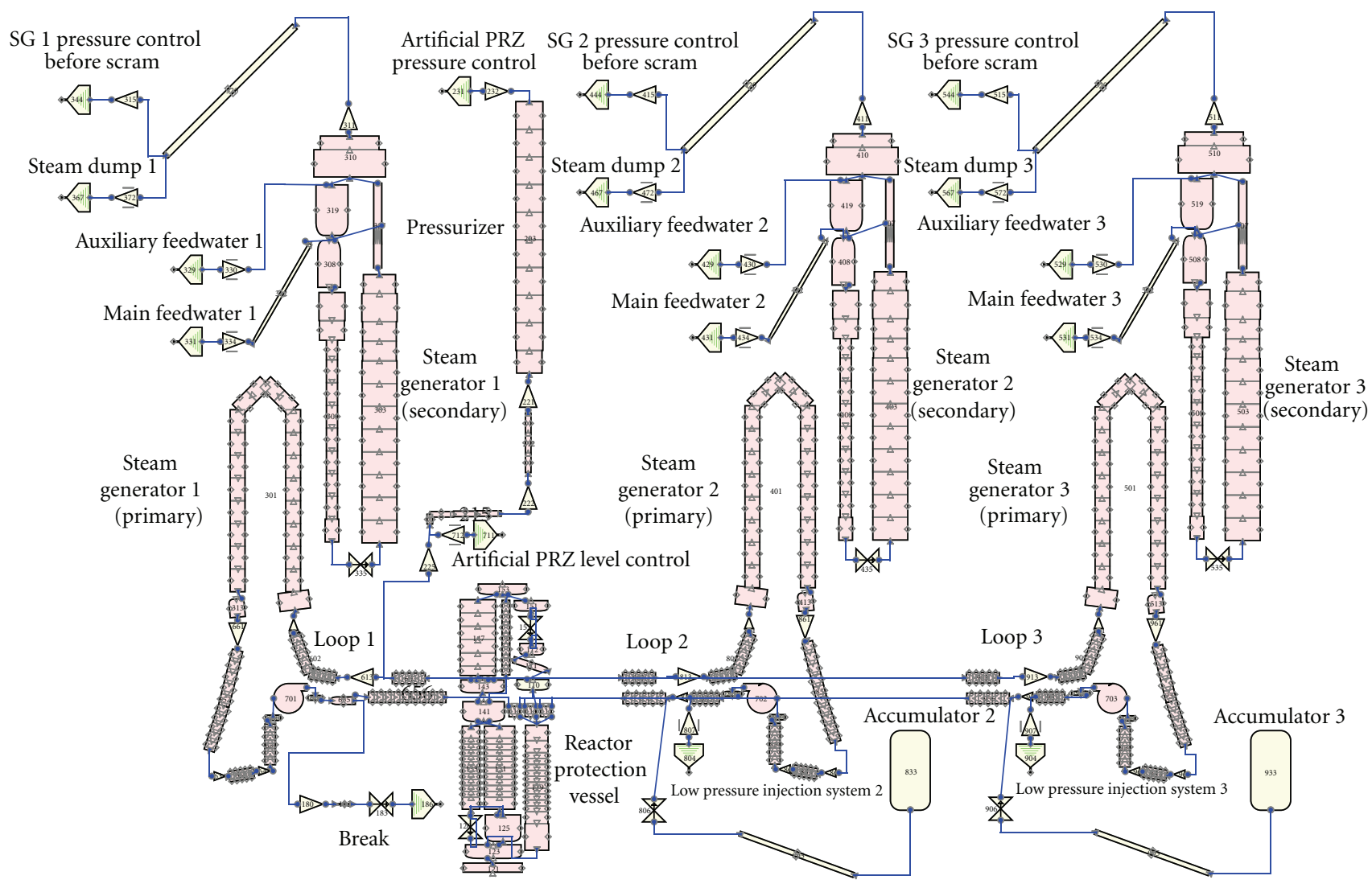

Figure 2: SNAP hydraulic components view for RELAP5/MOD3.3 input model of BETHSY 6.2TC transient.

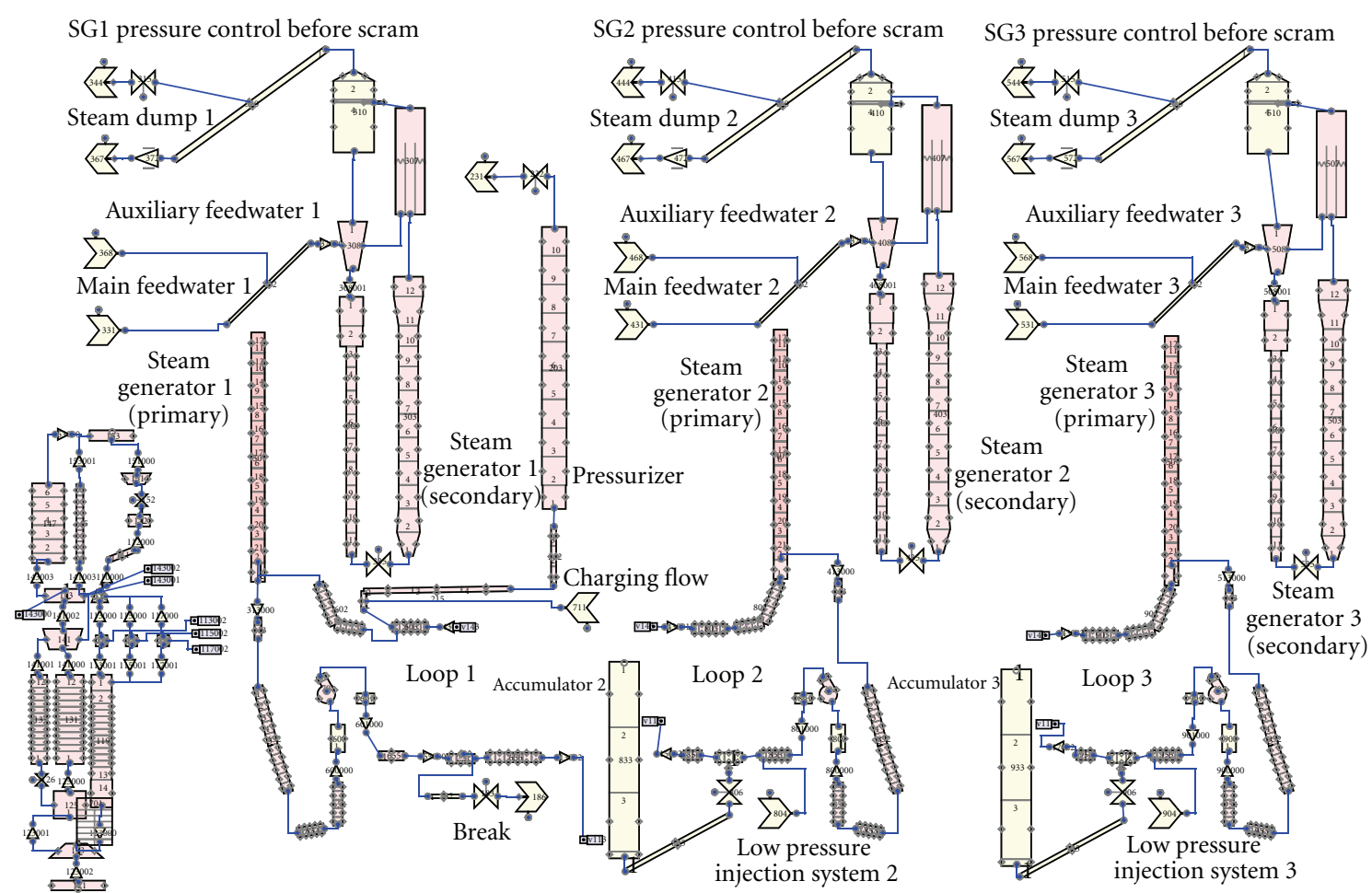

Reactor protection vessel

FIgURE 3: SNAP hydrodynamic components view for TRACE transient input model of BETHSY 6.2TC test. 
TABLE 1: Comparison of initial conditions for BETHSY 6.2TC test.

\begin{tabular}{|c|c|c|c|}
\hline Parameter & Measured & RELAP5 & TRACE \\
\hline Core thermal power $(\mathrm{kW})$ & $2863 \pm 30$ & 2864 & 2860 \\
\hline Pressurizer pressure $(\mathrm{MPa})$ & $15.38 \pm 0.15$ & 15.38 & 15.38 \\
\hline Pressurizer level (m) & $7.45 \pm 0.2$ & 7.45 & 7.45 \\
\hline Total flow $(\mathrm{kg} / \mathrm{s})$ & 16.81 (calculated from core power) & 16.84 & 16.61 \\
\hline Core inlet temperature $(\mathrm{K})$ & $557.2 \pm 0.4$ & 557.2 & 557.2 \\
\hline Core outlet temperature $(\mathrm{K})$ & $588.2 \pm 0.4$ & 588.1 & 588.8 \\
\hline Reactor coolant system mass (kg) & $1984 \pm 50$ & 1948 & 1948 \\
\hline Secondary side pressure per SG (MPa) & $6.84 \pm 0.07$ & 6.83 & 6.69 \\
\hline Steam generator level per SG (m) & $11.1 \pm 0.05$ & 11.1 & 11.1 \\
\hline Feedwater temperature $(\mathrm{K})$ & $523.2 \pm 4$ & 523.2 & 523.2 \\
\hline Heat loss $(\mathrm{kW})$ & 54.82 & N.A. & N.A. \\
\hline Downcomer to upper head flow $(\mathrm{kg} / \mathrm{s})$ & 0.047 & 0.047 & 0.047 \\
\hline
\end{tabular}

have either friction defined, or the abrupt area change model enabled. Solution was to input very small values of loss coefficients. This was needed for areas of components converted from the RELAP5 servo valves and accumulators.

Several important side junctions resulting from RELAP5 Branch components converted to TRACE Pipe components were renodalized using Tee components (e.g., break, accumulator injection point, steam generator dome). These specific adaptations were important for the calculation results. The break modeled by originally converted side junction produced different results in the steady state of BETHSY 9.1b test [20]. Similar was true for the accumulator injection. In the case of RELAP5 time-dependent junctions converted to TRACE Pump (type mass flow controlled single junctions) such adaptations were not needed. Nevertheless, such pump components were replaced by Fill components. Each Fill component replaces one volume and one junction component, what reduced the number of hydraulic components. Also, much of adaptation was needed for heat structures. In the RELAP5 input model the source of heating was realized by control variables. Therefore, in the converted TRACE input model several power components were generated. Unfortunately, by power components only the positive power can be modeled, while to model heat losses the heat structures should be powered by negative power. Therefore heat fluxes were assigned to the outer surfaces (the desired power divided by heat structure outer surface area), while power components were deleted all except the one representing the core heating.

Finally, it should be noted that TRACE has the capability to model and analyze three-dimensional components such as a reactor vessel. However, for this assessment the TRACE input model which was converted by SNAP from the RELAP5 input model using one-dimensional components. Namely, SNAP does not have the capability to convert onedimensional reactor vessel model into three-dimensional reactor vessel model. This has to be done manually.

2.5. Description of Computer Codes. The basic RELAP5 thermal-hydraulic model uses six equations: two mass conservation equations, two momentum conservation equations, and two energy conservation equations. Closure of the field equations is provided through the use of constitutive relations and correlations. Since the release of RELAP5/ MOD2 in 1985 the code was continuously improved and extended. New models were included like zirconium-water reaction model, level tracking model, thermal stratification model, countercurrent flow limiting correlation, and so forth. Several improvements to existing models were also done, for example Henry-Fauske and Moody choking flow models, new correlations for interfacial friction, modified reflood model, and new critical heat flux correlation for rod bundles. Finally, user conveniences have been added for code execution on a variety of systems. The latest version is RELAP5/MOD3.3 Patch 04, released in 2010. For more details on RELAP5 the reader can refer to [14].

TRACE was combined from four main system codes (TRAC-P, TRAC-B, RELAP5, and RAMONA), which were developed under US NRC to perform safety analyses of loss-of-coolant accidents and operational transients, and other accident scenarios in pressurized light-water reactors and boiling light-water reactors. TRACE can also model phenomena occurring in experimental facilities designed to simulate transients in reactor systems. TRACE includes models for multidimensional two-phase flow, nonequilibrium thermodynamics, generalized heat transfer, reflood, level tracking, reactor kinetics, and passive systems. The partial differential equations that describe two-phase flow and heat transfer are solved using finite volume numerical methods. The heat-transfer equations are evaluated using a semi-implicit time-differencing technique. A componentbased approach is used to modeling a reactor system. Each physical piece of equipment in a flow loop can be represented as some type of component, and each component can be further nodalized into some number of physical volumes (also called cells) over which the fluid, conduction, and kinetics equations are averaged. There is no built-in limit for the number of components or volumes that can be modeled; the size of a problem is theoretically only limited by the available computer memory. With hydraulic components 


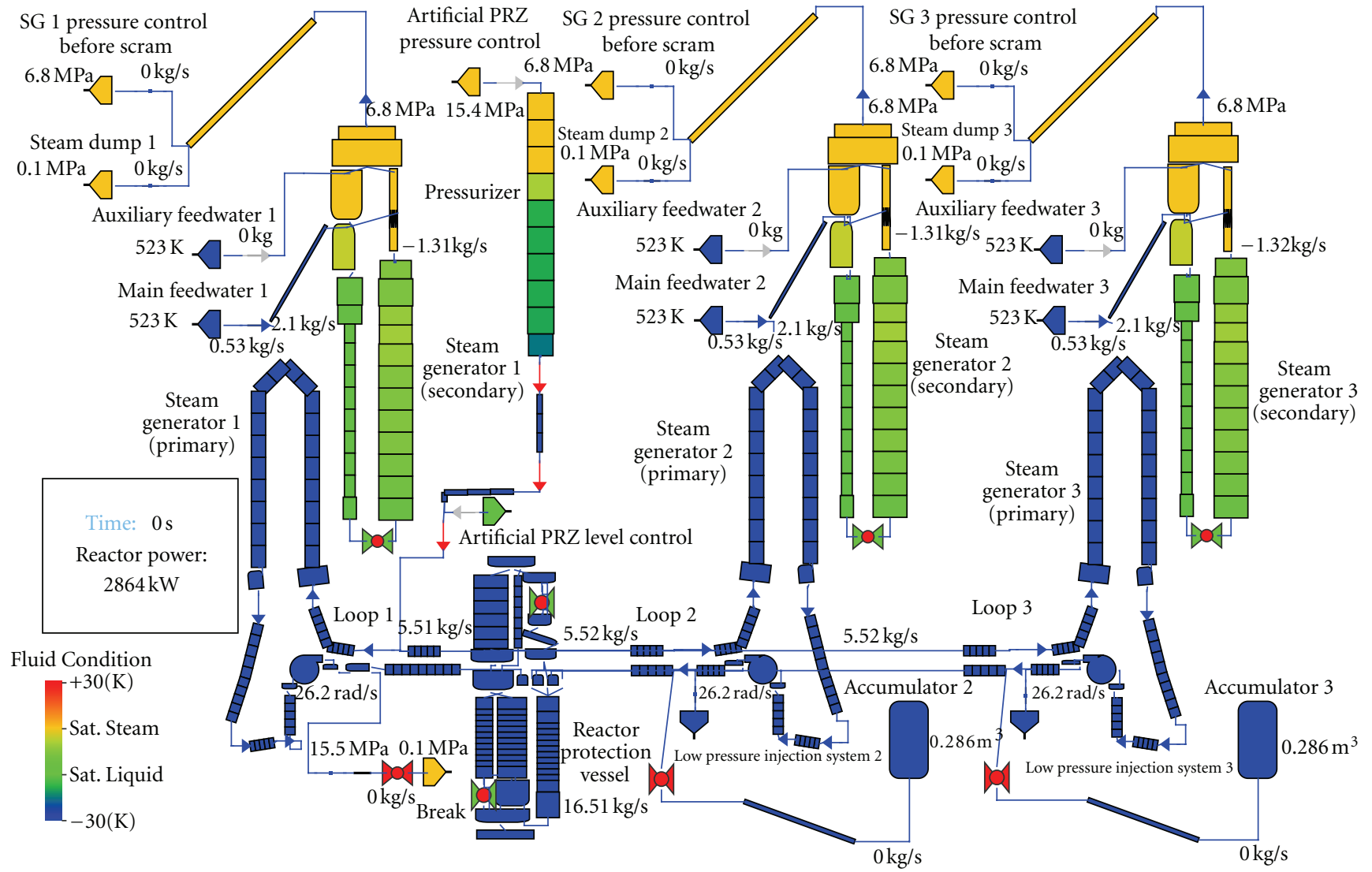

FIgURE 4: RELAP5 initial and boundary conditions for BETHSY 6.2TC test-animated view.

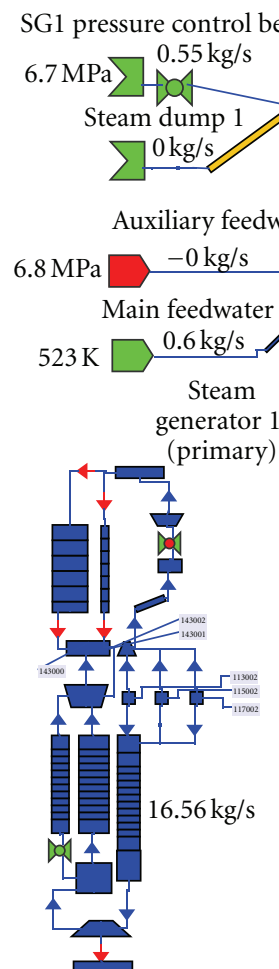

Reactor protection vessel

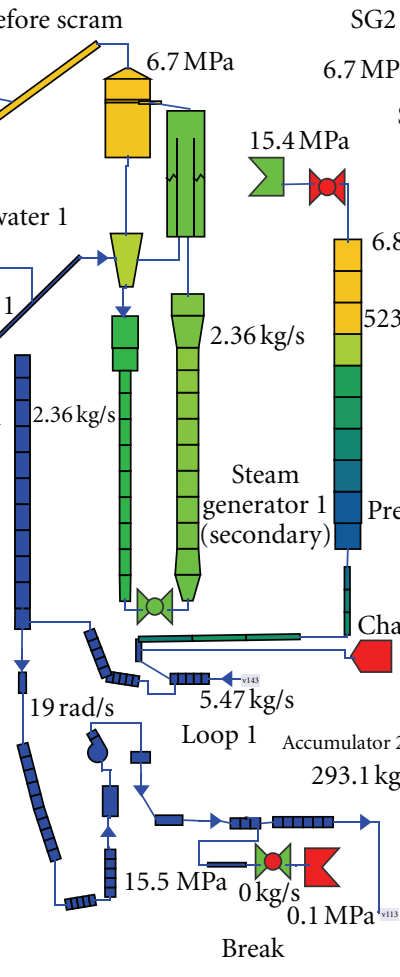

G2 pressure control before scram SG3 pressure control before scram

$\mathrm{MPa} \quad 0.55 \mathrm{~kg} / \mathrm{s} \quad 6.7 \mathrm{MPa} \quad 0.55 \mathrm{~kg} / \mathrm{s}$

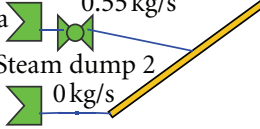

Auxiliary feedwater 2

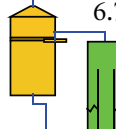

Steam dump 3 $\sum 0 \mathrm{~kg} / \mathrm{s}$

Auxiliary feedwater 3

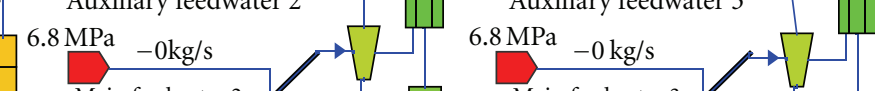

$523 \mathrm{~K}^{\text {Main feedwater } 2}$ I ${ }_{523} \mathrm{~K}^{\text {Main feedwater } 3}$

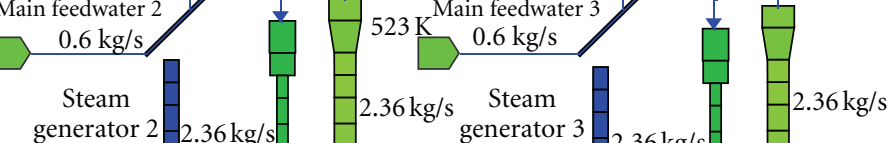

generator $2-2.36 \mathrm{~kg} / \mathrm{s}$

(primary)

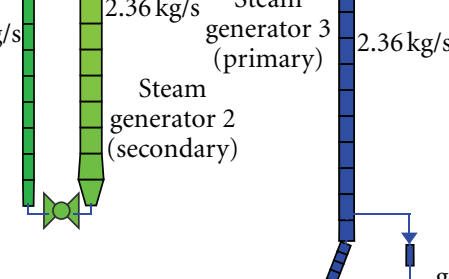

$5.47 \mathrm{~kg} / \mathrm{s} 19 \mathrm{rad} / \mathrm{s}$

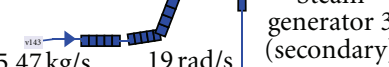

$5.47 \mathrm{~kg} / \mathrm{s} \quad 19 \mathrm{rad} / \mathrm{s}$ (secondary)

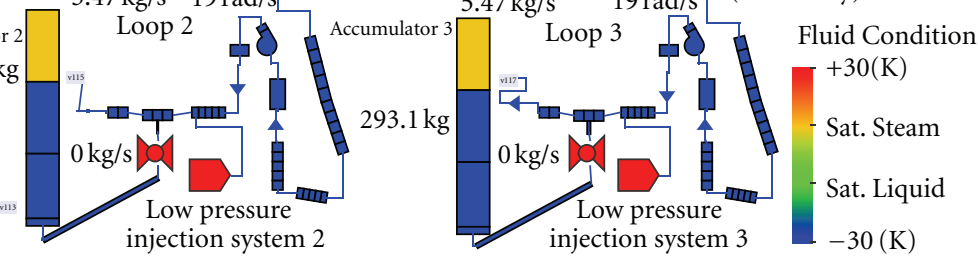

injection system 2

Time: $0 \mathrm{~s} \quad$ Reactor power: $2860 \mathrm{~kW}$

FIGURE 5: TRACE initial and boundary conditions for BETHSY 6.2TC test-animated view. 
TABle 2: Main sequence of events.

\begin{tabular}{lccc}
\hline Events & & Time $(\mathrm{s})$ & TRACE \\
\hline Break opening & Experiment & RELAP5 & 0 \\
Scram signal (13.1 MPa) & 0 & 0 & 3 \\
Safety injection signal (11.7 MPa) & 8 & 2 & 9 \\
First core uncover & 12 & 8 & 136 \\
Loop seal clearing & 92 & 90 & 173 \\
Primary/secondary pressure reversal & 134 & 155 & 203 \\
Second core uncovery & 172 & 175 & 253 \\
Accumulator no. 2 and 3 injection start (4.2 MPa) & 334 & 365 & 329 \\
Accumulator isolation no. 2 (no. 3) (1.5 MPa) & 345 & 925 & 801 \\
Pressurizer pressure $<0.7 \mathrm{MPa}$ & $948(976)$ & 2230 & 2167 \\
\hline
\end{tabular}

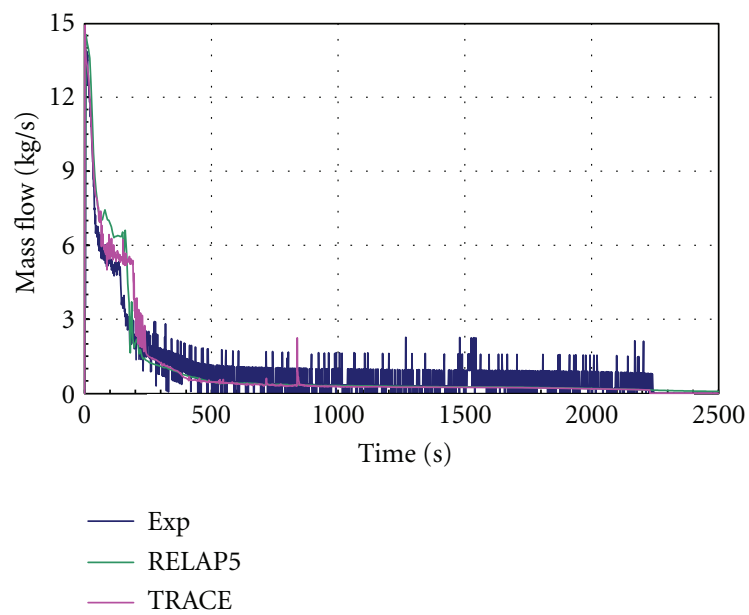

FIgURe 6: Mass flow rate at the break.

the pipes, pressurizer, upper and lower plenum of the reactor vessel, pumps, separators, tees, valves, reactor vessel with associated internals, and containment. There are also heat structures and components for boundary condition and break. For more details on TRACE the reader can refer to [1].

SNAP [2] consists of a suite of integrated applications designed to simplify the process of performing engineering analysis. SNAP is intended for creating and editing input for engineering analysis codes and it has functionality for submitting, monitoring, and interacting with the codes. SNAP currently support the CONTAIN, COBRA, FRAPCON3, MELCOR, PARCS, RADTRAD, RELAP5, and TRACE analysis codes. Each code is supported by a separate plugin. SNAP's interactive and postprocessing capabilities are predominately realized within its animation displays. Within such a display, the results of a calculation may be animated in a variety of ways. An animation display retrieves data from the server and represents it visually in some fashion. The data can be from an actively running calculation, a completed calculation, external data, and so forth.

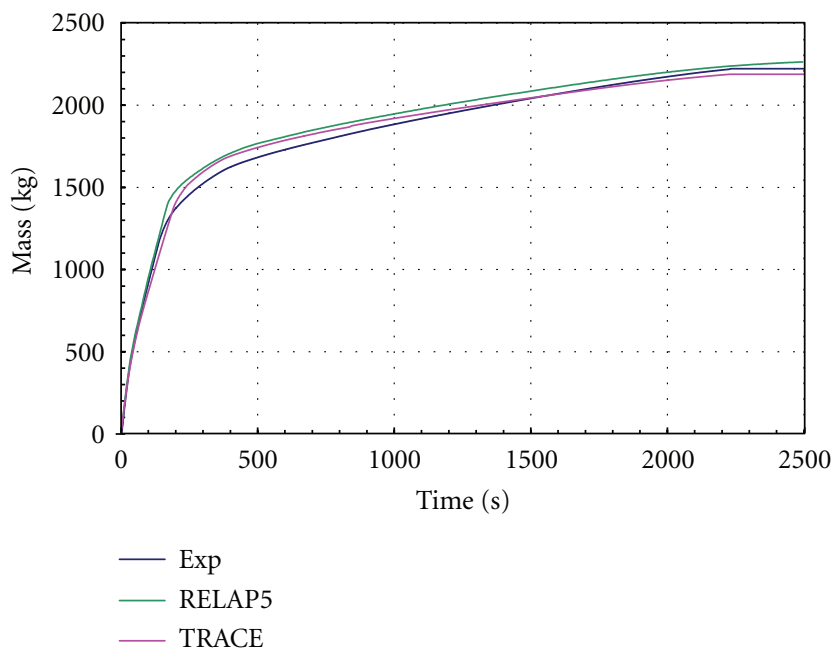

FIGURE 7: Integrated mass flow rate at the break.

\section{Results}

The results of steady-state and transient calculations of BETHSY 6.2TC test using TRACE V5.0 Patch 1 and RELAP5/ MOD3.3 Patch 4 computer codes are presented in the following subsections. The results are presented in classical way with graphs and in advanced way as animated representations of calculation results.

3.1. Steady-State Calculation. The comparison between calculated and measured initial conditions for BETHSY 6.2TC test is shown in Table 1. The RELAP5 and TRACE input models were initialized to the cold leg temperature rather to secondary pressure. The secondary pressure is then dependent on the heat transfer across the steam generators. In the case of TRACE the secondary pressure is not perfectly matched. The difference comes from the geometry and the code models. For example, in the TRACE assessment report [13] the cold leg temperature was not matched for the sake of matching the secondary pressure. The steam generator levels and masses were matched to measured values both 


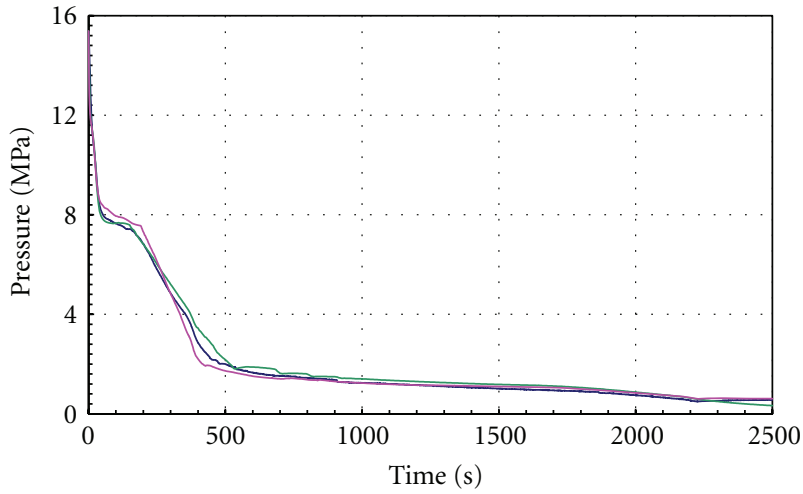

- Exp

- RELAP5

— TRACE

Figure 8: Pressurizer pressure.

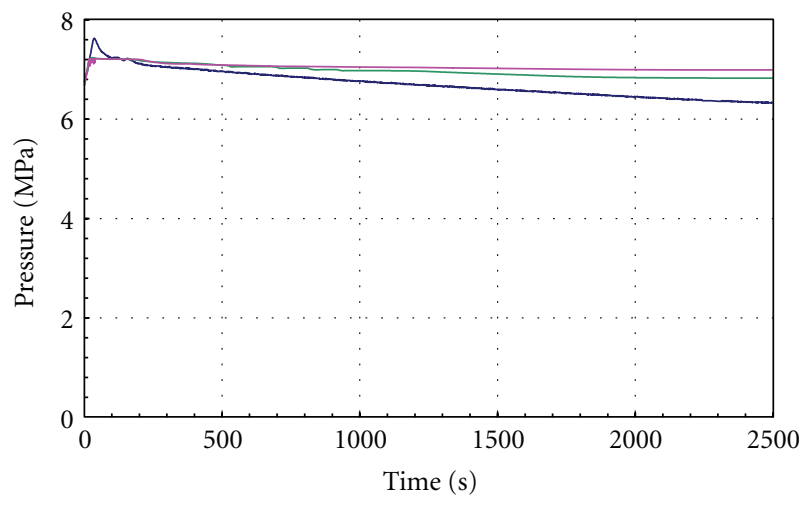

- Exp

- RELAP5

— TRACE

FIGURE 9: Secondary pressure.

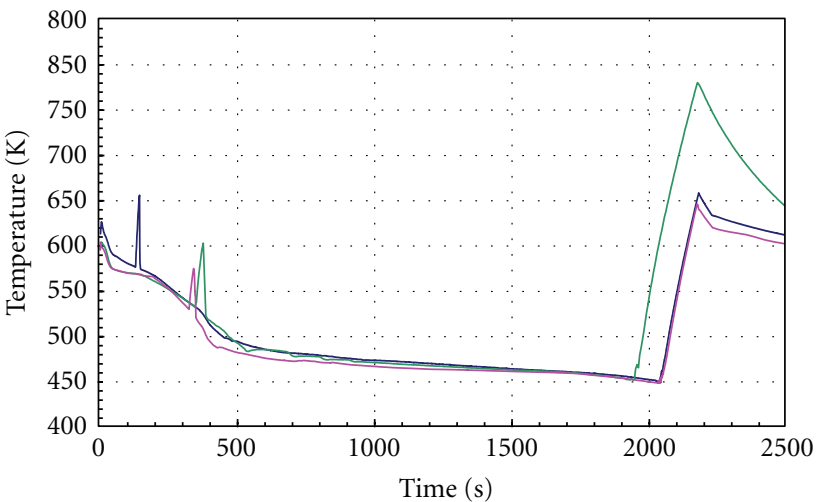

$$
\begin{aligned}
& - \text { Exp } \\
& - \text { RELAP5 } \\
& - \text { TRACE }
\end{aligned}
$$

Figure 10: Heater rod surface temperature at the middle of the core.
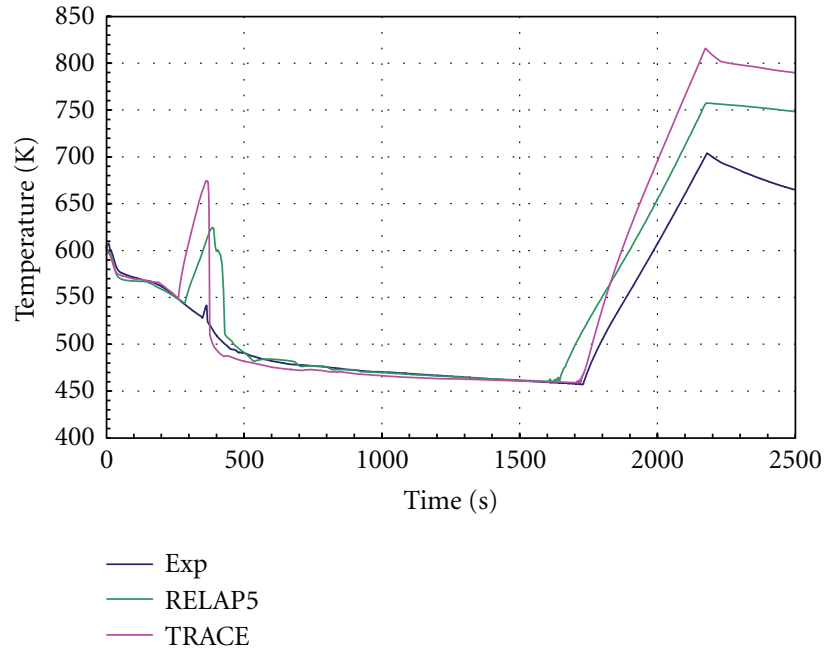

FIGURE 11: Heater rod surface temperature at the top of the core.

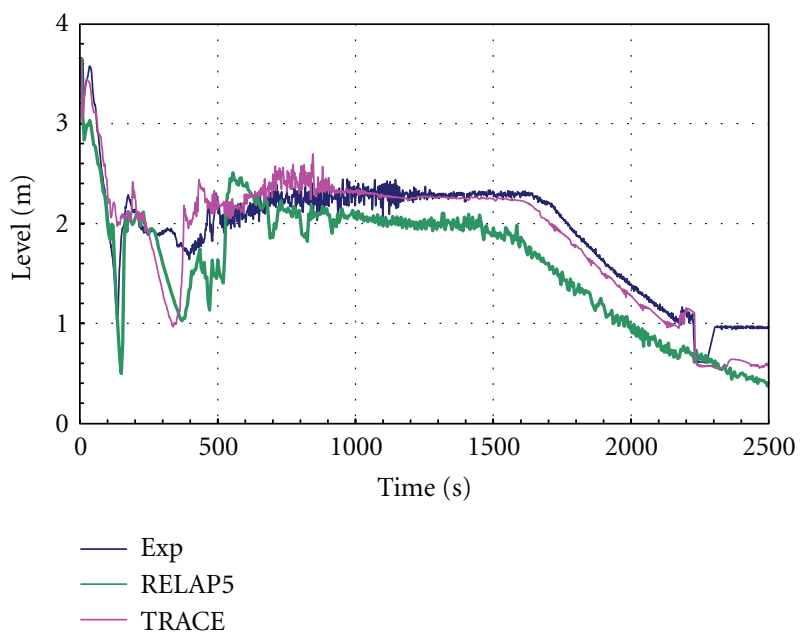

FIgURE 12: Core-collapsed liquid level.

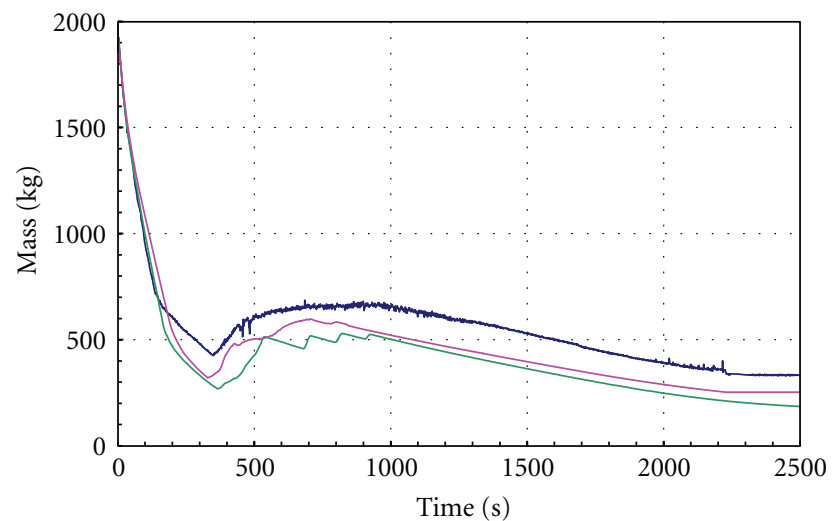

Exp
- RELAP5
- TRACE

FIgURE 13: Primary circuit total mass. 


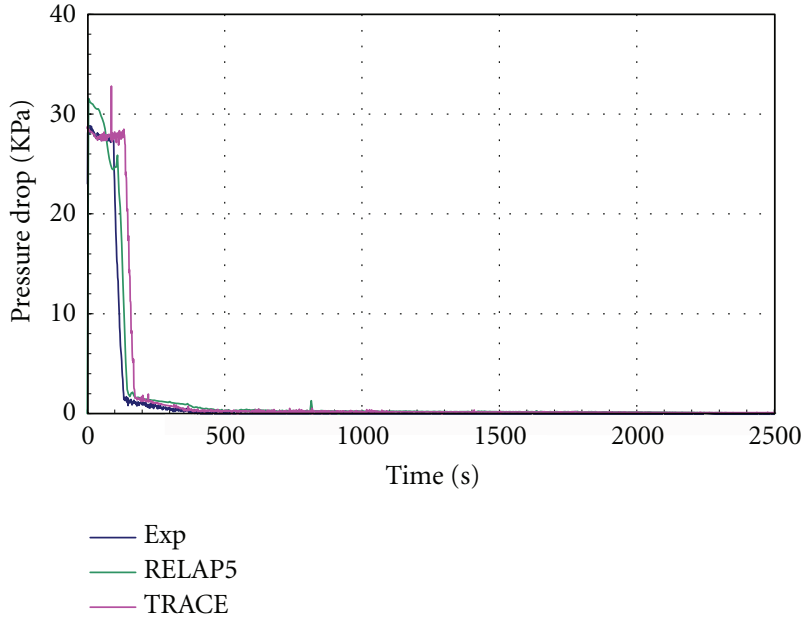

FIgURE 14: Intermediate leg 1 DP (SG side).

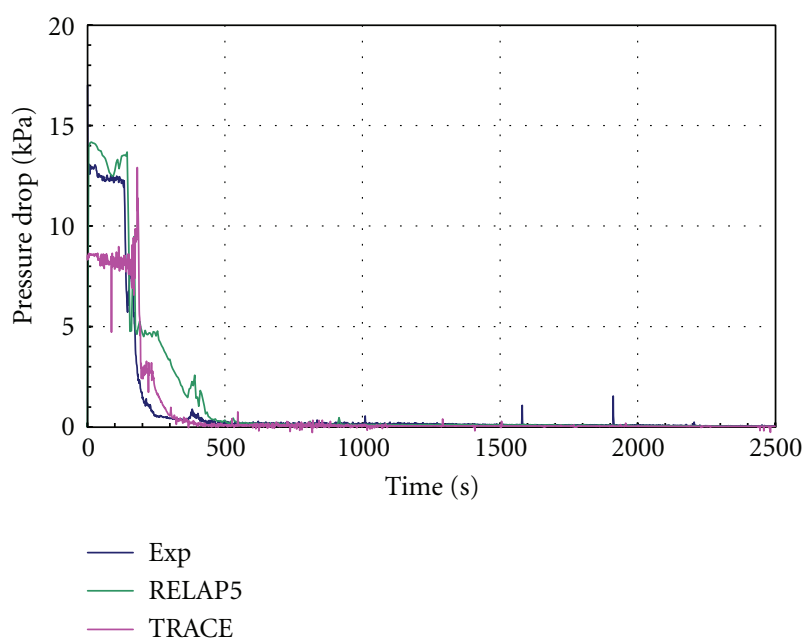

Figure 15: Intermediate leg 1 DP (pump side).

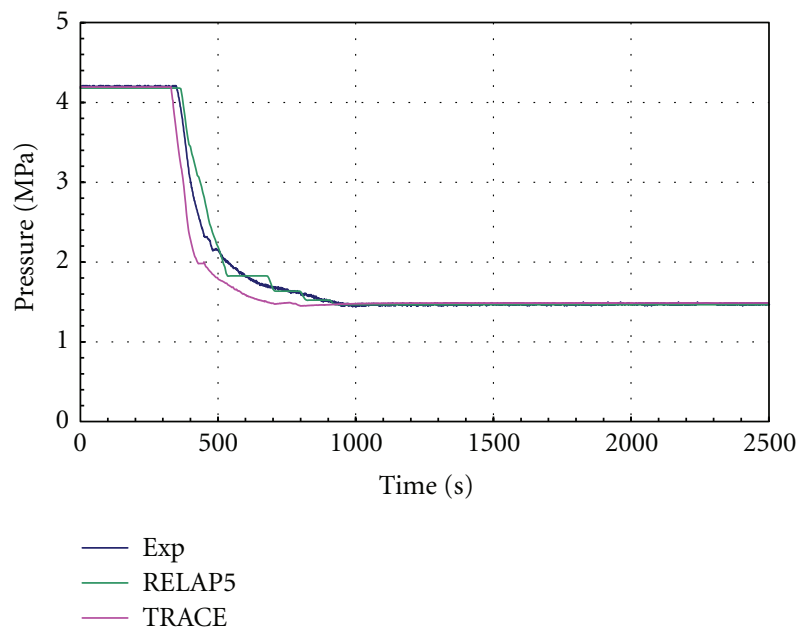

Figure 16: Accumulator number 2 pressure.

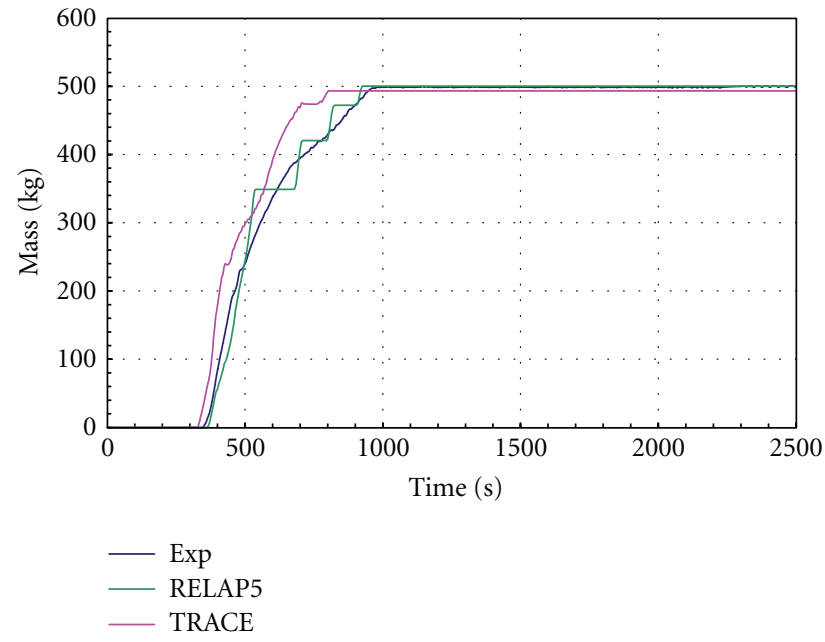

FIgURE 17: Integrated accumulators injected mass.

for RELAP5 and TRACE. The pressurizer pressure and level were also matched to measured values. The core power was boundary condition. In the experiment the electrical trace heating system was installed of the power of $54.82 \mathrm{~kW}$ and was operating till the transient start. Therefore in the calculations the heat losses were modeled after the electrical trace heating system was turned off.

The TRACE input model was initialized using built in artificial controls, which were obtained by conversion from RELAP5 and then simplified by introducing Fill components. The primary pressure was set by boundary condition, while the pressurizer level was set by an artificial Fill component. The controller to set the desired cold leg temperature was also used. For steam generator level the Fill component was used (using the Fill component simulating auxiliary feedwater during transient). The primary mass flow was adjusted by the pump speed. Figures 4 and 5 show the animation masks of BETHSY facility for RELAP5 and TRACE, respectively. On the masks the fluid condition color map is used and data values are shown at time $0 \mathrm{~s}$, that is, presenting the calculated initial and boundary conditions. It can be seen that primary side is filled with subcooled liquid except the pressurizer, which is filled with saturated liquid and saturated steam at the top. On the secondary side the bottom parts of steam generators are saturated liquid, while at the top there is saturated steam. Please also note, that in Figure 5 for TRACE Fills and Breaks the status is shown instead of fluid condition. Green color means the Fill or Break component is active and red color means it is off. The initial conditions shown in Figures 4 and 5 are complement to the values given in Table 1.

3.2. Transient Calculation. The main sequence of events is shown in Table 2. The comparison between the experiment and RELAP5 and TRACE calculated results is shown in Figure 6 through Figure 17. The calculation results showed that occurrences and trends of key transient phenomena are reasonably predicted by both computer codes. 


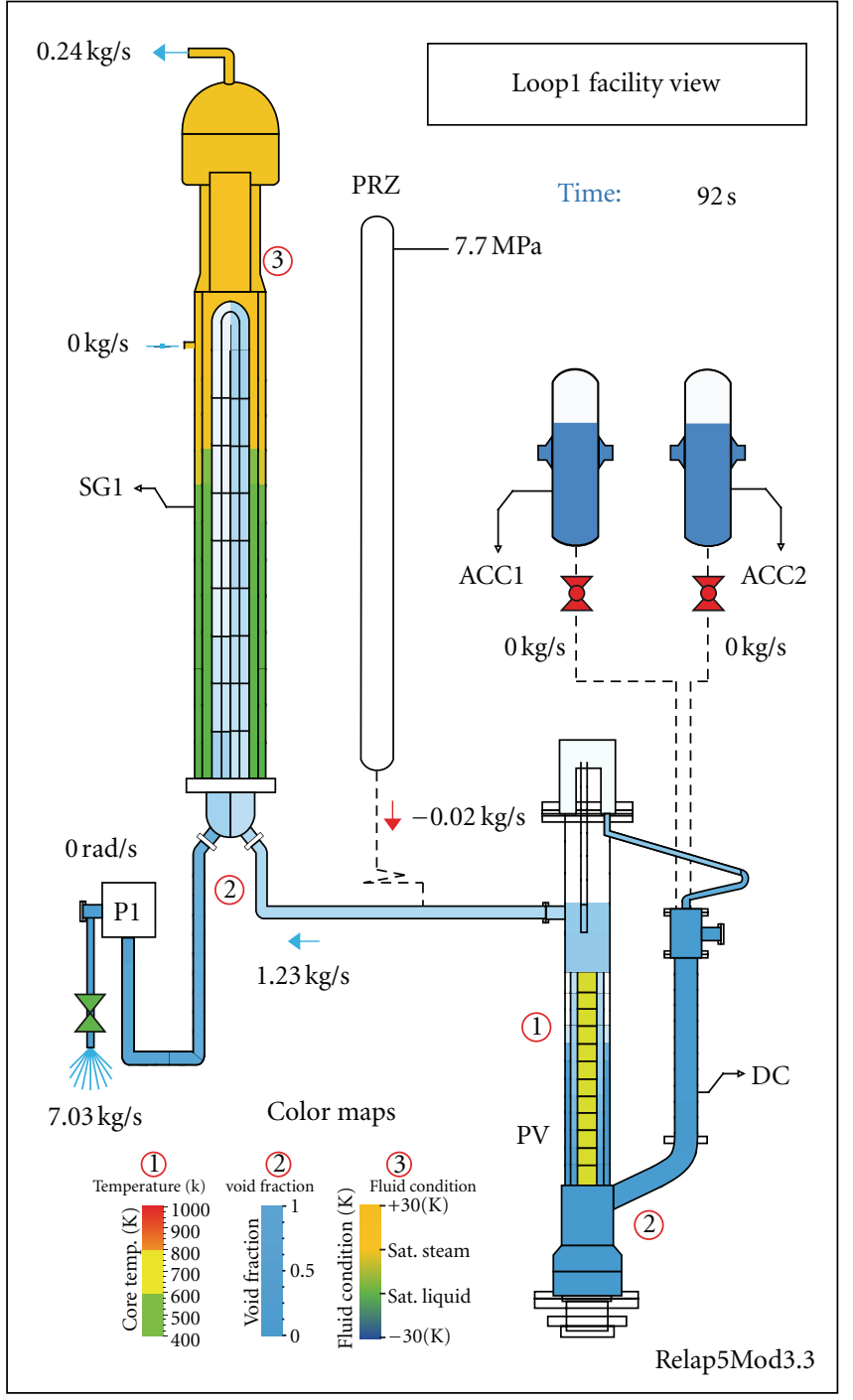

(a)

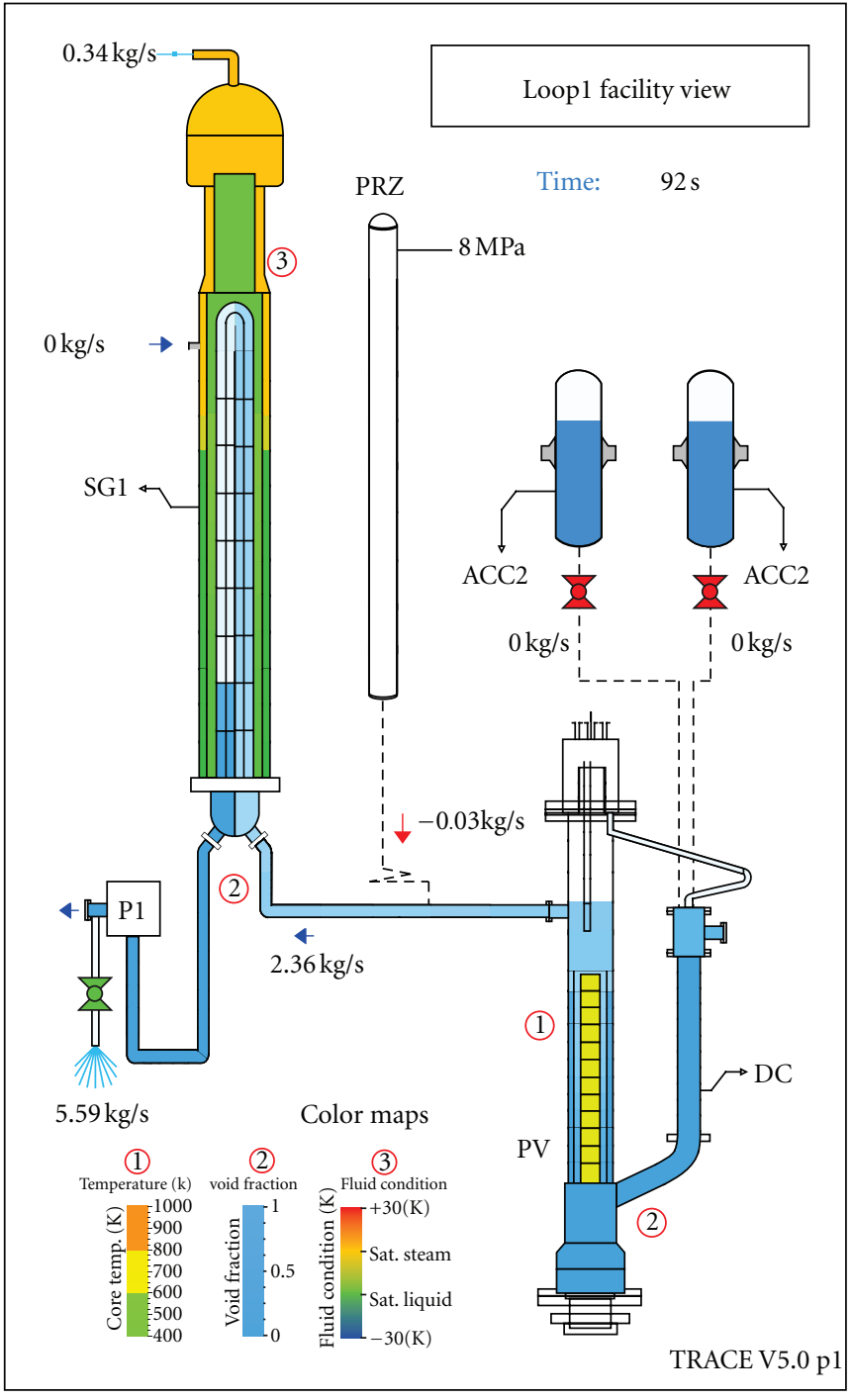

(b)

Figure 18: Animation mask for RELAP5 (a) and TRACE (b) at time $t=92 \mathrm{~s}$ (first core uncovery).

As shown in Table 2 most of event times were reasonably captured. The reactor trip time and safety injection signal actuation time are similar for both RELAP5 and TRACE calculation. Because the pressure drop in TRACE calculation is slower than in the experiment, the primary to secondary pressure reversal is delayed in the case of TRACE. The main reason is probably the secondary side behavior. Namely, the mass released through atmospheric relief valves in the initial period greatly influenced the primary pressure drop. Higher measured secondary pressure indicated that in the first $100 \mathrm{~s}$ the atmospheric relief valves were open few tens of seconds only, while in the calculation the pressure was controlled to $7.2 \mathrm{MPa}$ according to test procedure. The overall accumulator time performance is better for RELAP5 than for TRACE calculation.

The timing of the transient very much depends on the mass flow rate at the break. For RELAP5 original RansomTrapp break flow model the values of $0.85,1.25$ and 0.75 were used for subcooled, two-phase, and superheated discharge coefficient, respectively. For TRACE break model the values of 0.8 and 0.9 were used for subcooled and two phase discharge coefficients, respectively. The values for TRACE were selected after some sensitivity studies. In Figures 6 and 7 are shown the mass flow rate at the break and integrated mass flow rate at the break. It can be seen that the calculated break flows are quite well matched, in the range of $10 \%$ uncertainty. The integrated mass flow rate at the break better agree for the TRACE calculation. Primary pressure is shown in Figure 8. In spite of larger RELAP5 mass flow rate at the break than TRACE mass flow rate at the break the pressure drop is faster in case of TRACE calculation. Secondary pressure is shown in Figure 9. Already it was noted, that experimental values indicated that atmospheric relief valves were open a few tens of seconds. The agreement between experiment and calculation is slightly better for RELAP5 than for TRACE. Nevertheless, in general after initial period the secondary 

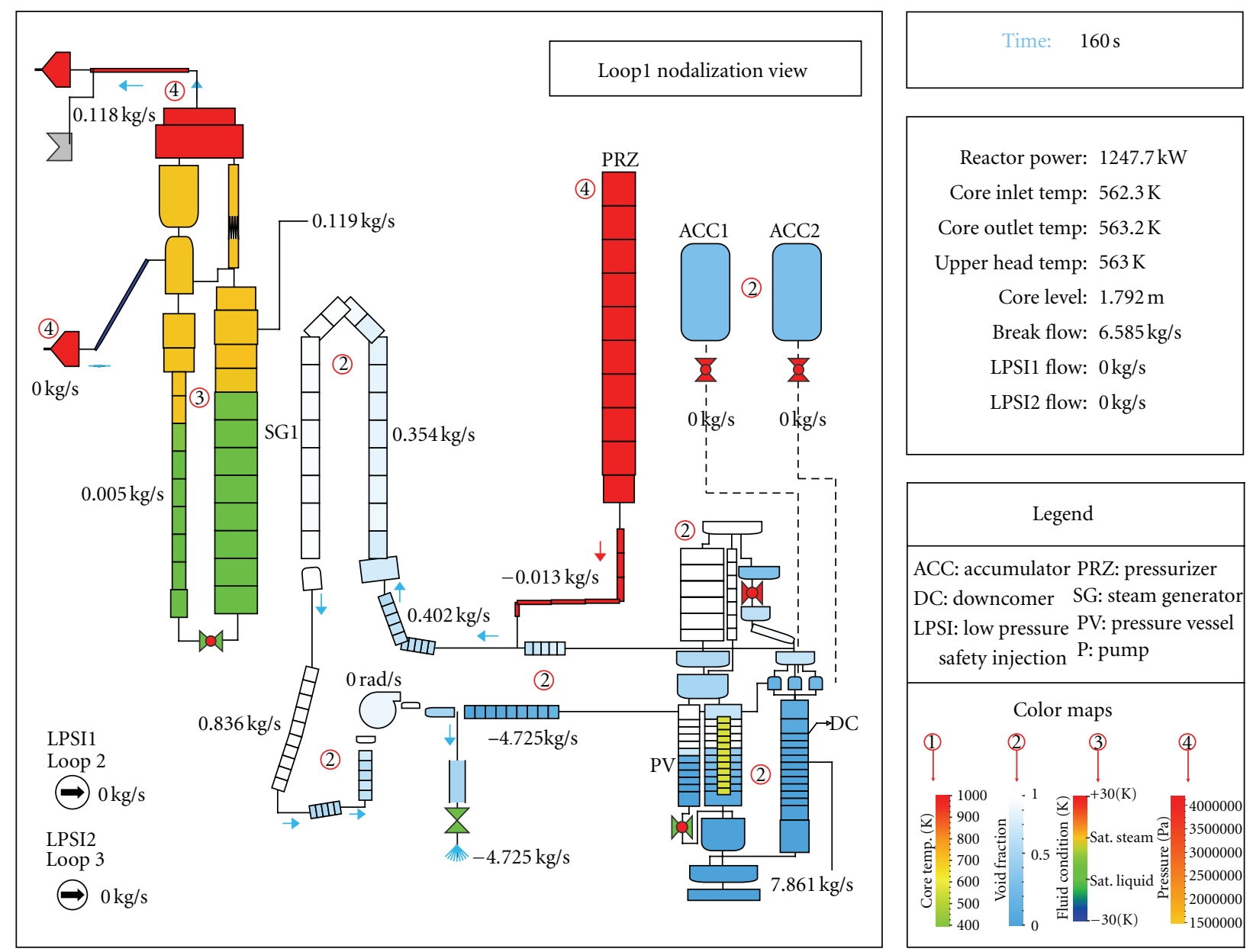

FIgURE 19: Animation mask for RELAP5 at time $t=160 \mathrm{~s}$ (after loop seal clearance).

side has small influence on the primary side and by this on the overall calculation. Figures 10 and 11 show the heater rod surface temperatures in the middle and at the top of the core, respectively. The core heatup time corresponds by the minimum core collapsed liquid level shown in Figure 12. Both calculations predicted with delay the first peak of heater rod surface temperature at the middle of the core. The second rod heatup was better calculated by TRACE. In the case of heater rod surface temperature at the top of the core the timing of heatup prediction was better in the case of TRACE, while heatup rate was better in the case of RELAP5. The primary circuit total mass is shown in Figure 13. In spite of correct TRACE calculated mass discharged through the break the TRACE calculated primary mass is smaller than the experimental. It should be noted that uncertainty in mass was reported to be $50 \mathrm{~kg}$. In the case of RELAP5 calculation the core level was lower, while RELAP5 calculated discharged mass was slightly lower than TRACE. The reason is that slightly larger mass discharged through the break was calculated by RELAP 5 than by TRACE. It can be concluded that TRACE is more consistent when comparing both the core level and mass in the primary system. The information on the loop seal clearing can be obtained from Figures 14 and 15 , showing the differential pressures on the steam generator and pump side, respectively. It may be seen that some further adjustment is needed for TRACE initial pressure drop on the pump side. Finally, the accumulator behavior is shown in Figure 16 showing the accumulator pressure and Figure 17 showing the integrated accumulator injected mass. The trend for RELAP5 is very good but the discharge is not smooth, while in the case of TRACE the accumulator discharged faster than in the experiment but smoothly like in the experiment.

3.3. Results Discussion. Comparison of TRACE and RELAP5 calculations show that in general there are very similar. It was confirmed that TRACE using the converted input model from RELAP5 produced results comparable to RELAP5. Such finding was confirmed in the study of BETHSY 9.1b test [20], being TRACE is even slightly better than RELAP5. When looking the timing of accumulator injection and core heatup in the presented BETHSY 6.2TC test, the presented TRACE calculation was better than the calculation reported in TRACE assessment manual [13].

3.4. Code Comparison through Animation Masks. Time trends are very good to show the time progression of the variables, while animation masks can give snapshots at certain times for the whole facility condition. This 

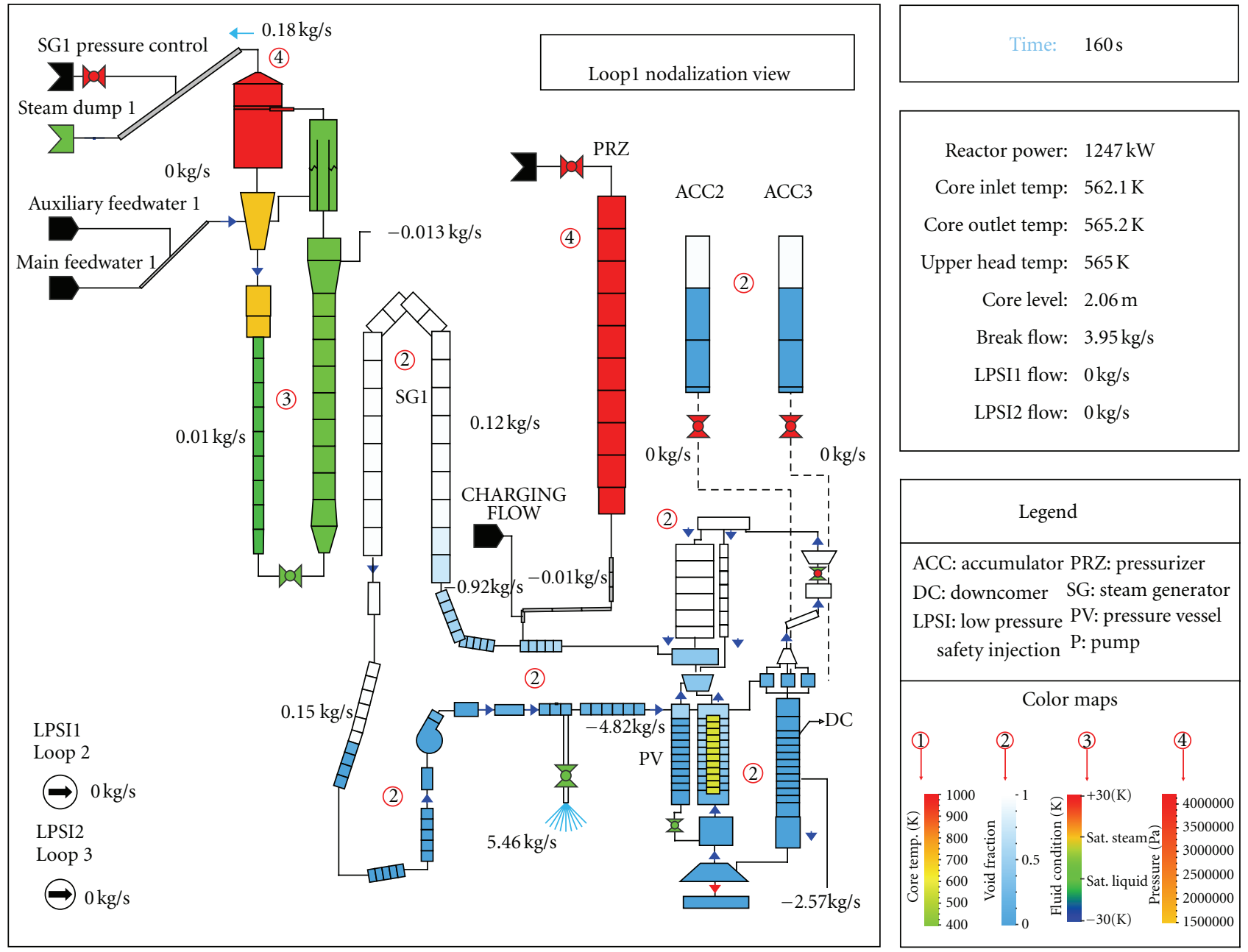

FIgURE 20: Animation mask for TRACE at time $t=160 \mathrm{~s}$ (before loop seal clearance).

is especially important when there is a need to follow distribution of liquid, temperature, pressure, and any other variable around the loop. To follow the time progression, a movie can be generated too. For the purpose of this paper the snapshots at important events are shown. The components are labeled with number in circles, designating which color map is used by component. The color map no. 1 represents the core temperature (i.e., heat structure temperature). It is used just for core heat structures. Namely, other heat structures are not shown in the mask. The color map no. 2 is void fraction color map, blue color presenting the fluid and white color presenting the gas. The color map no. 3 is fluid condition color map. The subcooled liquid is in blue color, the saturated liquid is in green, and the saturated gas is in orange color. When the temperature is $30 \mathrm{~K}$ above saturation temperature, the red color is used. The color map no. 4 is pressure color map. The color goes from orange to red, where red color represents higher pressure.

In Figure 18 it is shown the loop 1 BETHSY facility mask at $92 \mathrm{~s}$, at which the core in the experiment first uncovered. From Figure 18 it can be seen that much of primary circuit is filled with liquid, except pressurizer and upper head, both for RELAP5 (a) and TRACE calculation (b). By this the statement in the experiment description is confirmed [21]: "The hot parts of the primary circuit (upper head, upper plenum, SG U-tubes) started to boil. The formation of loop seal causes the core level depression." It can be also seen that accumulators are partially filled. The color map no. 3 is used to show the condition on the secondary side of steam generator. For RELAP5 the steam generator is in the saturation condition, in the lower part of downcomer and riser is saturated liquid and in the upper part of steam generator is saturated steam. In the case of TRACE in the separator component there is saturated liquid. Please refer to Section 2.4 for problems we had with modeling. Namely, the separator components could not be replaced with Pipe components, since the input model fail to run, therefore the separator was retained in the model. The fluid condition in other TRACE components is very similar to the corresponding RELAP5 components. Also it can be seen that accumulators are not injecting at this time. Finally, from Table 2 and Figure 12 it can be seen that the timing of core uncovery is good for RELAP5, while in the case of TRACE this uncovery is later. This finding is supported by Figure 18, 


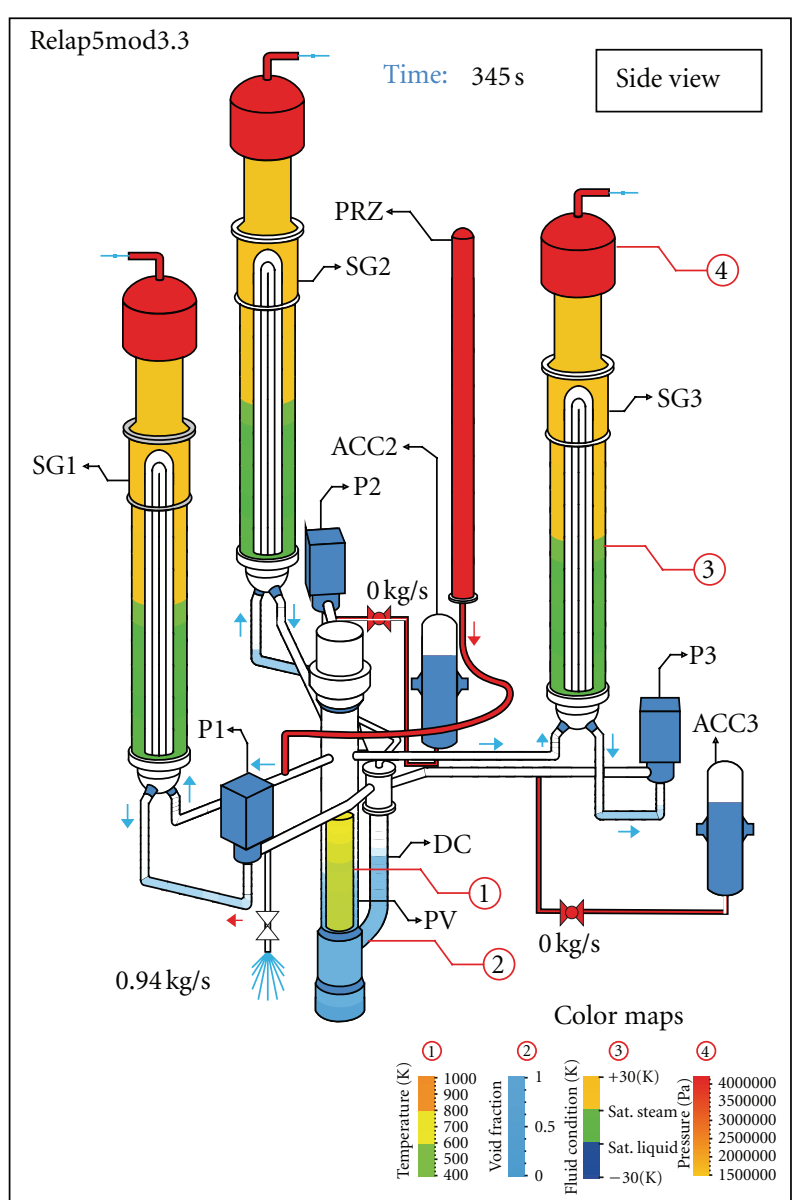

(a)

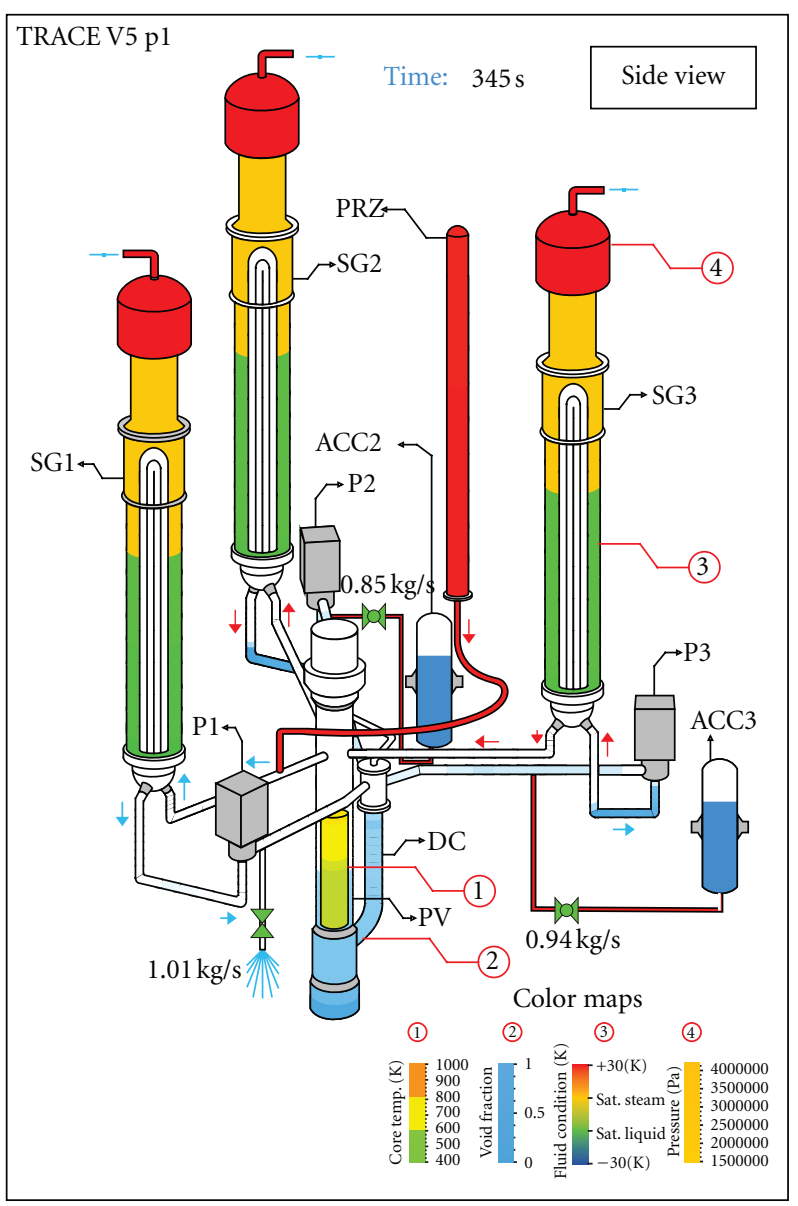

(b)

FIgURe 21: Animation mask for RELAP5 (a) and TRACE (b) at time $t=345 \mathrm{~s}$ (loop seal clearance).

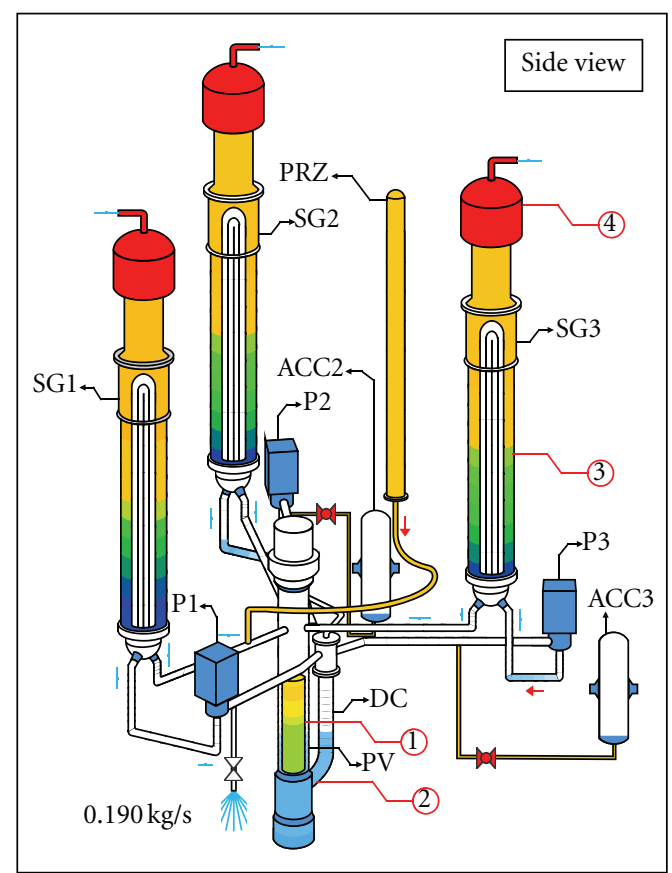
Time: $2000 \mathrm{~s} \quad$ Core outlet temp.: $447.1 \mathrm{~K}$ Reactor power: $278.1 \mathrm{~kW} \quad$ Upper head temp.: $447.1 \mathrm{~K}$
Break flow: $0.190 \mathrm{~kg} / \mathrm{s}$ Core inlet temp.: $448.2 \mathrm{~K}$ Core level: $0.936 \mathrm{~m}$ LPSI flow: $0 \mathrm{~kg} / \mathrm{s}$

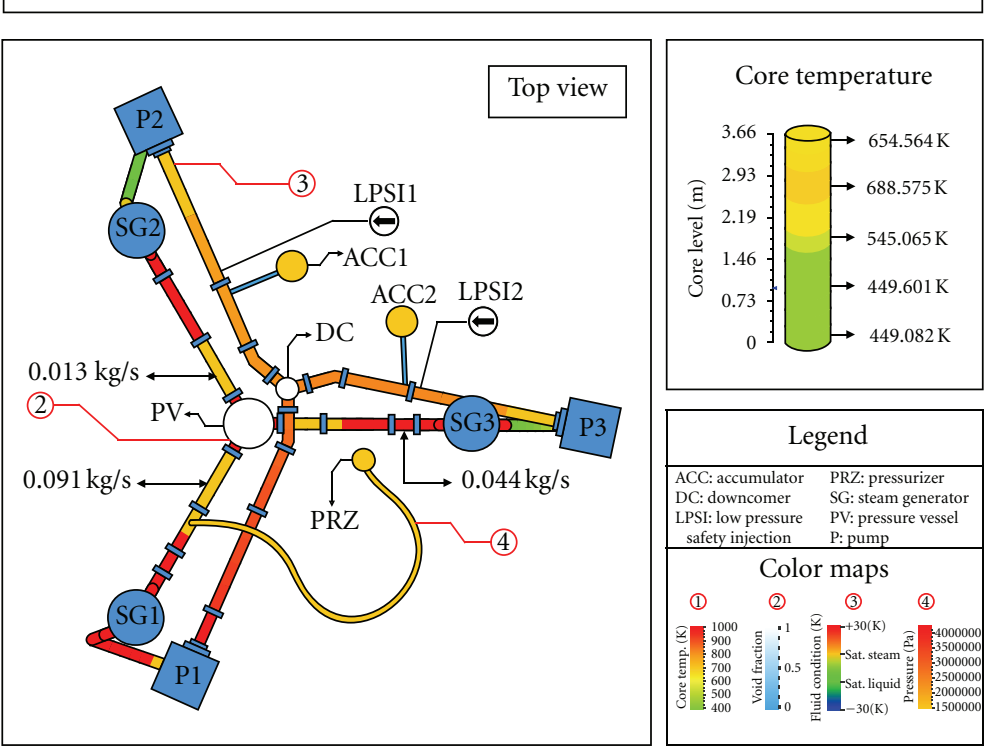

FIGURE 22: Animation mask for RELAP5 at time $t=2000 \mathrm{~s}$ (core heatup). 

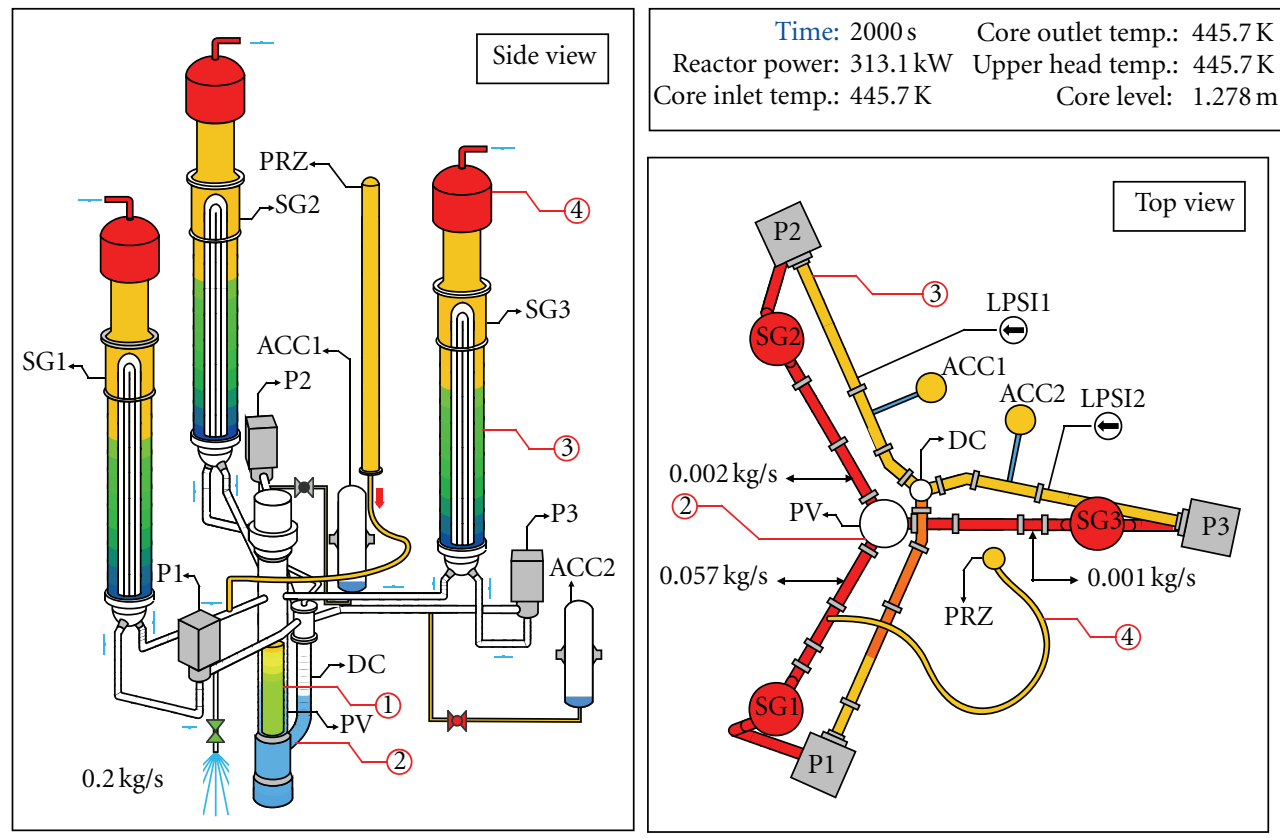
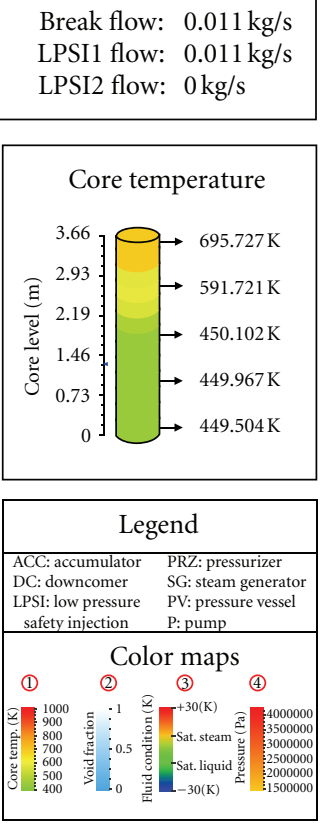

Figure 23: Animation mask for TRACE at time $t=2000 \mathrm{~s}$ (core heatup).

where uncovery can be seen for RELAP5 calculation, while this is not the case for TRACE calculation.

Next important event shown is loop seal clearing at time $134 \mathrm{~s}$. Both RELAP5 and TRACE calculation predicted loops seal clearing with delay, therefore the time $160 \mathrm{~s}$ was selected. At that time the loop seal cleared in the case of RELAP5 calculation (Figure 19), while in the case of TRACE the loop seal can still be seen (Figure 20). In the case of RELAP5 low level was also reached in the core (as in experiment), while TRACE calculation did not predict significant first core uncovery at the time $160 \mathrm{~s}$. It can also be seen that pressure in the steam generator and pressurizer is above $4.5 \mathrm{MPa}$ what prevents injection by accumulators in both calculations, which is also in agreement with the experimental data.

In the experiment the accumulator injection started in 345 s. From Table 2 we can see that at this time in the TRACE calculation the accumulator is injecting, while in the RELAP5 calculation the accumulator started to inject later at $363 \mathrm{~s}$. Figure 21 shows the BETHSY facility animated with four color maps. For the primary circuit void fraction color map is used. The numerical values of break flow rate and accumulator flow rate are given. In the case of TRACE both accumulators are injected, and the total injection mass flow rate is larger than the break mass flow rate.

At time $976 \mathrm{~s}$ the accumulator injection was terminated in the test. There is no other injection available and the primary circuit mass started to decrease. At $2000 \mathrm{~s}$ the core started to uncover again resulting in the core heatup. Figures 22 and 23 are rather complex animation masks displaying side view and top view of the BETHSY facility and core heat structure at $2000 \mathrm{~s}$. Four color maps are used for animations. The side view of the facility shows that most liquid is present in the lower part of the reactor vessel. Some amount of liquid remained in the accumulators due to their closure. The situation is similar for both calculations. The top view of both calculations shows that all three loops are in the saturated condition. Finally, from the core temperatures it can be seen that the rods start to heat from top to the bottom because of uncovering the core from top to the bottom.

\section{Conclusions}

The overall results obtained with TRACE V5.0 Patch 1 using converted one-dimensional reactor vessel model were comparable to the results obtained by RELAP5/MOD3.3 Patch 4 . The results show that the main discrepancies in the case of TRACE calculation are connected with the predictions of primary pressure and break flow in the first $200 \mathrm{~s}$, influencing the accumulator emptying and primary mass inventory. Both the TRACE and RELAP5 code predicted first core uncovery until accumulators started to inject and after emptying accumulators the second core heatup was predicted due to second core boil off. It was shown that TRACE calculations obtained by converted input model from RELAP5 to TRACE are as good as the RELAP5 calculations obtained by the original RELAP5 input model. In addition the results were compared by animation masks, presenting several physical phenomena and processes as well as data values of variables and status of equipment. The results suggested that such advanced comparison analysis technique between two codes is beneficial because several in-depth insights into analysis results can be obtained.

\section{Acknowledgments}

The authors acknowledge the financial support from the state budget by the Slovenian Research Agency Program no. 
P2-0026 and financial support from Slovenian Nuclear Safety Administration and Krško Nuclear Power Plant by Project no. POG-3473.

\section{References}

[1] U. S. Nuclear Regulatory Commission, TRACE V5.0 User Manual, Division of Risk Assessment and Special Projects, Office of Nuclear Regulatory Research, Washington, DC, USA.

[2] APT, Symbolic Nuclear Analysis Package (SNAP), User's Manual. Report, Applied Programming Technology (APT), Inc., 2011.

[3] G. L. Mesina, "Visualization of RELAP5-3D best estimate code," in Proceedings of the International Meeting on Updates in Best Estimate Methods in Nuclear Installation Safety Analysis (BE '04), pp. 314-323, Washington, DC, USA, November 2004.

[4] W. P. Baek, J. E. Yang, and J. J. Ha, "Safety assessment of KOREAN nuclear facilities: current status and future," Nuclear Engineering and Technology, vol. 41, no. 4, pp. 391-402, 2009.

[5] J. D. Talley, S. Kim, J. Mahaffy, S. M. Bajorek, and K. Tien, "Implementation and evaluation of one-group interfacial area transport equation in TRACE," Nuclear Engineering and Design, vol. 241, no. 3, pp. 865-873, 2011.

[6] F. Mascari, G. Vella, B. G. Woods et al., "Sensitivity analysis of the MASLWR helical coil steam generator using TRACE," Nuclear Engineering and Design, vol. 241, no. 4, pp. 1137-1144, 2011.

[7] J. Freixa and A. Manera, "Analysis of an RPV upper head SBLOCA at the ROSA facility using TRACE," Nuclear Engineering and Design, vol. 240, no. 7, pp. 1779-1788, 2010.

[8] E. Coscarelli, A. Del Nevo, and F. D’Auria, “Qualification of TRACE v5 code against fast cooldown transient in the PKL-III integral test facility," in Proceedings of the 14th International Topical Meeting on Nuclear Reactor Thermal Hydraulics (NURETH-14), Toronto, Canada, September 2011, paper no. 419.

[9] U.S. NRC, "Status of CAMP activities in Slovenia," in Proceedings of the Fall CAMP Meeting, Williamsburg, VA, USA, November 2009.

[10] U.S. NRC, "SNAP Status Report," in Proceedings of the Fall CAMP Meeting, State College, Pa, USA, October 2010.

[11] U.S. NRC, "SNAP overview and plans," in Proceedings of the Fall CAMP Meeting, Philadelphia, Pa, USA, November 2011.

[12] S. Petelin, B. Mavko, O. Gortnar, I. Ravnikar, and G. Černe, "Result of BETHSY test 9.1.b using RELAP5/MOD3," International Agreement Report NUREG/IA-0141, U.S. Nuclear Regulatory Commission, Washington, DC, USA, 1998.

[13] U.S. Nuclear Regulatory Commission, TRACE V5.0 Assessment Manual, Division of Risk Assessment and Special Projects, Office of Nuclear Regulatory Research, Washington, DC, USA.

[14] U.S. NRC, "RELAP5/MOD3.3 code manual," Patch 04, Vols. 1 to 8, Information Systems Laboratories, Inc., Rockville, Md, USA, Idaho Falls, Idaho, prepared for USNRC, 2010.

[15] CEA, "BETHSY, General Description," Note SETh/LES/9097, CEA (Commissariat à l'énergie atomique et aux énergies alternatives), Grenoble, France, 1990.

[16] S. Belsito, F. D’Auria, M. Ingegneri, E. Chonjacki, and R. Gonzalez, "Post test analysis of counterpart tests in LOBI, SPES, BETHSY; LSTF facilities performed with the CATHARE2 code," in Proceedings of the Nuclear Energy in Central Europe (NECE '96), Portorož, Slovenia, September 1996.
[17] A. Prošek, "RELAP5 calculations of bethsy 9.1b test," Science and Technology of Nuclear Installations, vol. 2012, Article ID 238090, 11 pages, 2012.

[18] S. Hrvatin, A. Prošek, and I. Kljenak, "Quantitative assessment of the BETHSY 6.2 TC test simulation," in Proceedings of the 8th International Conference on Nuclear Engineering, The American Society of Mechanical Engineers, The American Society of Mechanical Engineers, 2000.

[19] S. Hrvatin and A. Prošek, "Quantitative assessment of the BETHSY 6.9c test simulation," in Proceedings of the International Conference Nuclear Energy in Central Europe, Bled, Slovenia, September 2000.

[20] A. Prošek and O. A. Berar, "Analysis of small-break loss-ofcoolant accident test $9.1 \mathrm{~b}$ at BETHSY facility with TRACE and RELAP5," in Proceedings of the International Congress on Advances in Nuclear Power Plants (ICAPP '11), Nice, France, May 2011.

[21] G. Briday and D. Juhel, "BETHSY-test 6.2 TC, 6 inch cold leg break counterpart test,” Tech. Rep. STR/LES/91-034, 1991. 

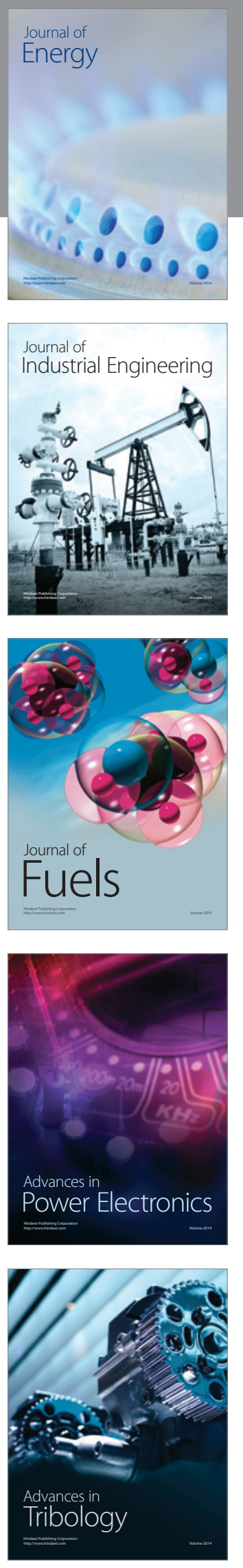
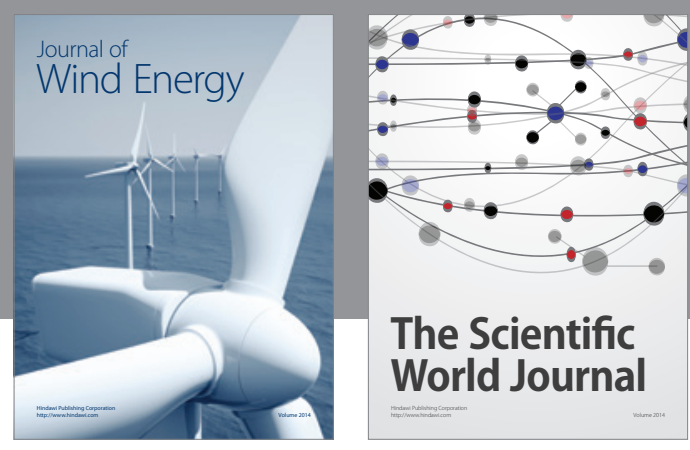

The Scientific World Journal

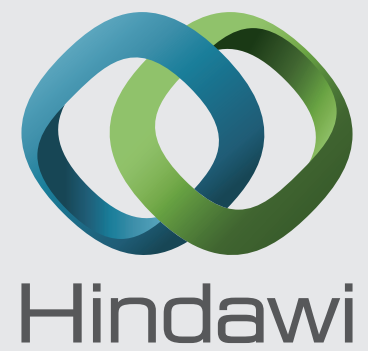

Submit your manuscripts at http://www.hindawi.com
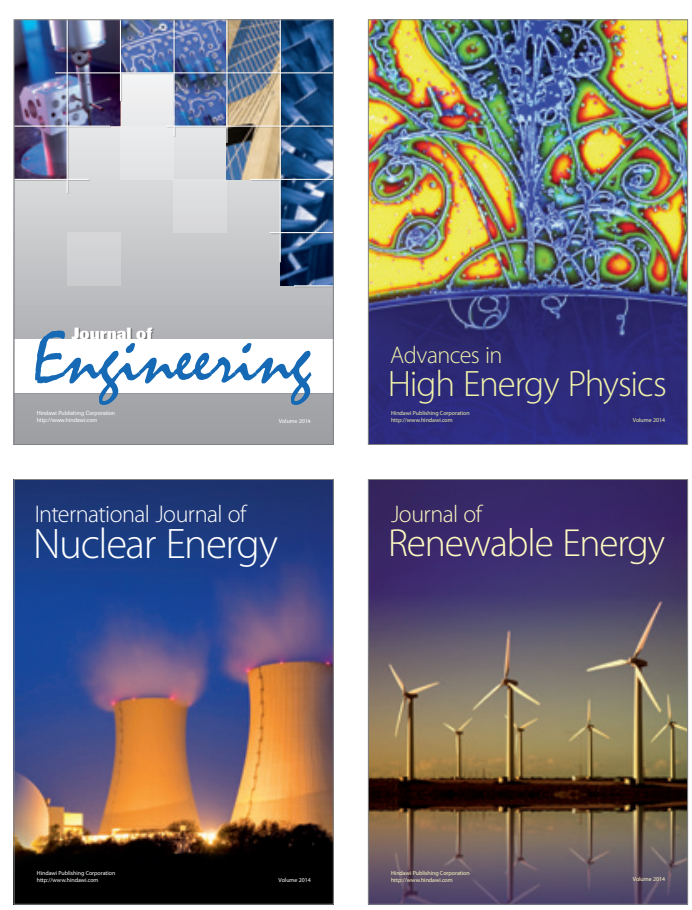

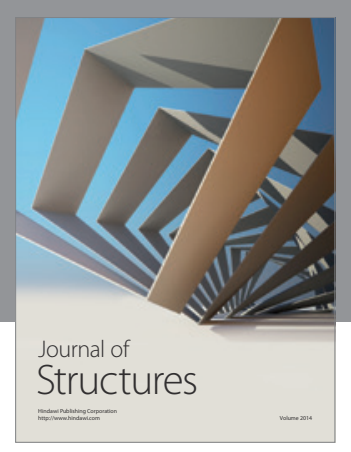

Rotating
Mechinery
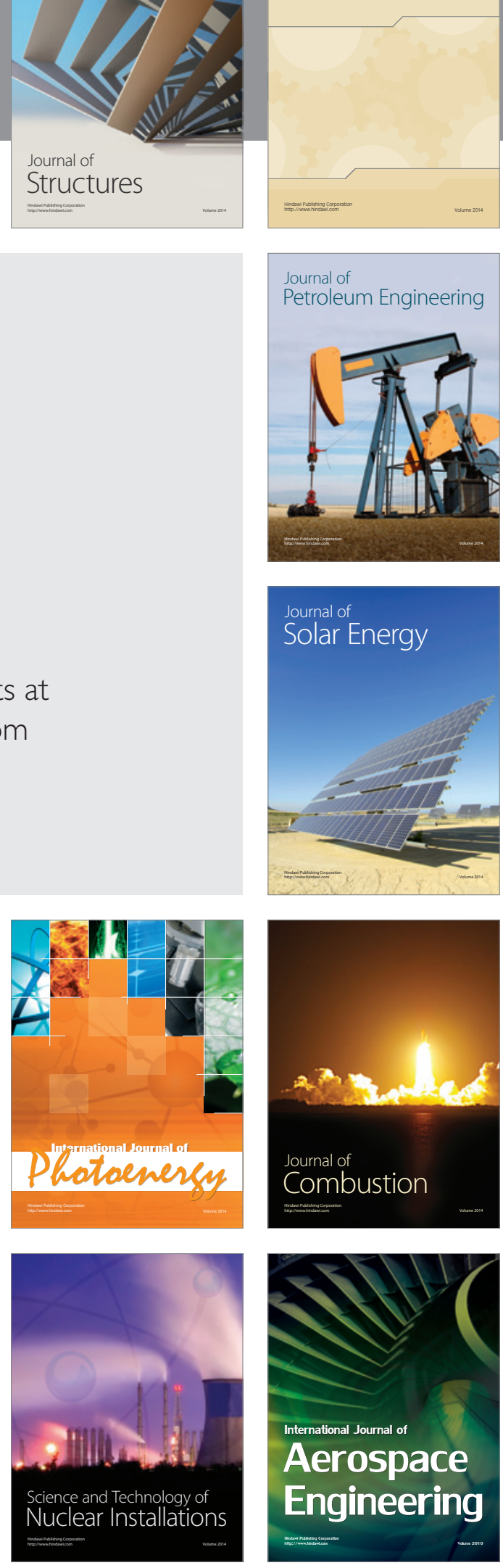